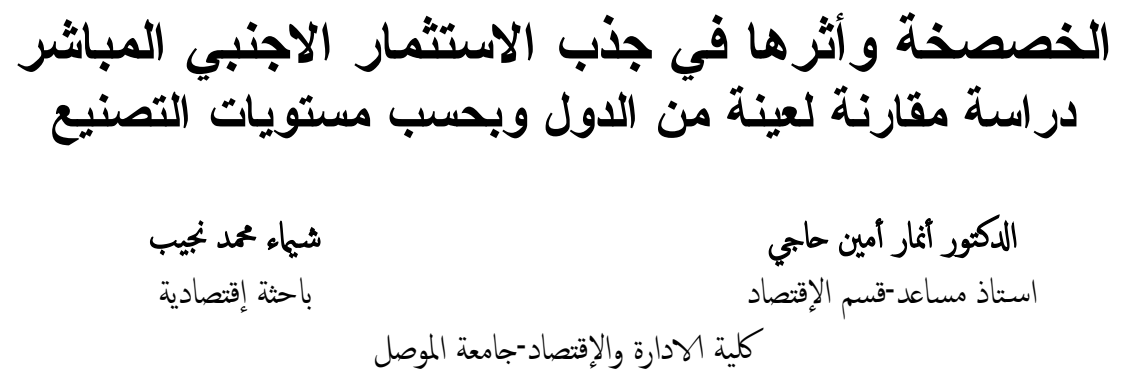

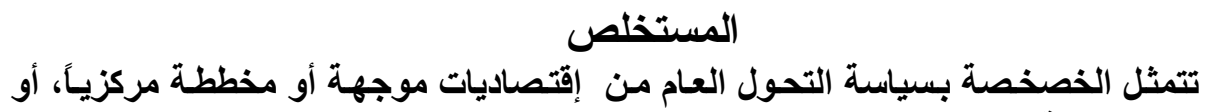
إقتصاديات مختلطة إلى إقتصاد لئير بلئلي.

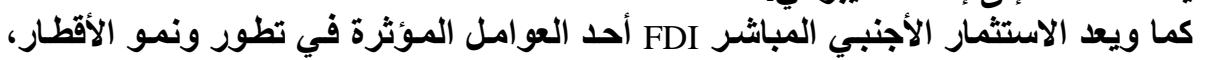

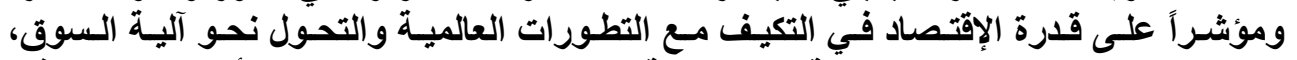

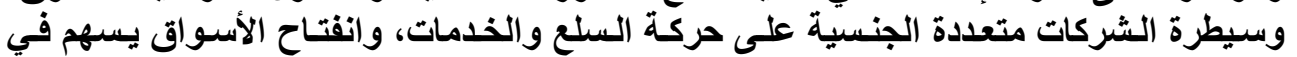
زيادة حجم التدفقات المالية نحو الأقطار.

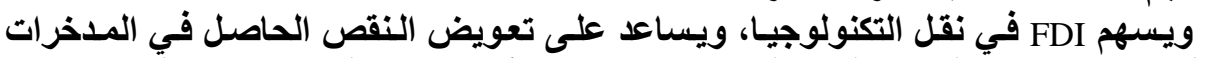

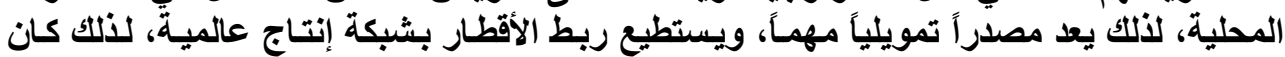

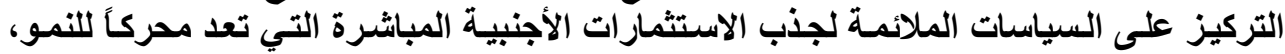

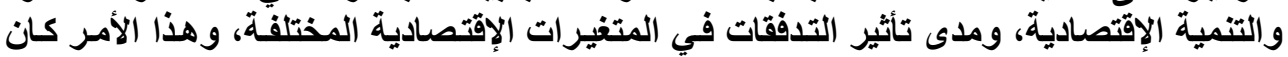

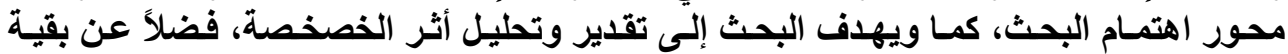

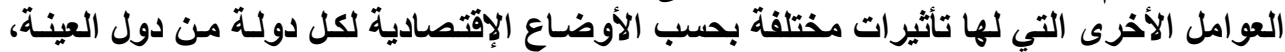

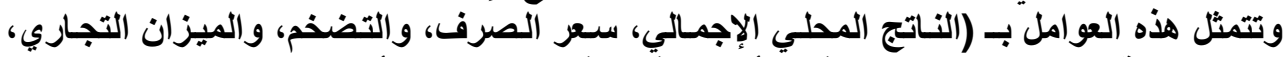

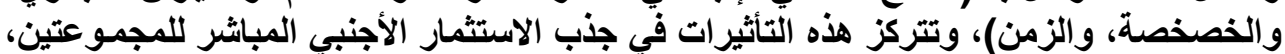

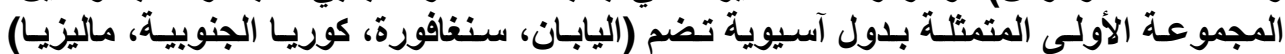

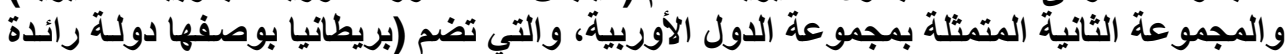

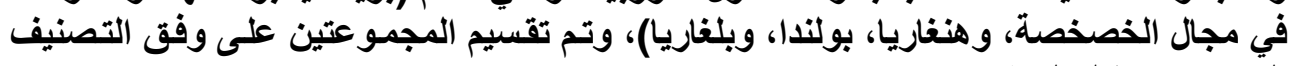
الصناعي، خلال المدة 1980-2003. 


\title{
A Comparative Study of a Sample of Countries According to the Levels of Manufacturing
}

\author{
Anmar A. Haji (PhD) \\ Assistant Professor \\ Department of Economics \\ University of Mosul
}

\author{
Shaimaa M. Najeeb \\ Economic researcher \\ Department of Economics \\ University of Mosul
}

\begin{abstract}
Privatization means a transformation from the public sector into the private sector by means of the sale of the losing institutions in the public sector to companies or individuals from the private sector. General transformation policy is known from socialist economies centrally drawn up various economies to the new liberal economic system. Countries have adopted form programs for its economies to enable them preparing the economy and the society for this transformation and privatization is the last stage in the process of transformation into free market system. Foreign direct investment is considered one of the effective factors in the growth and development of states and an index of economic ability to accommodate with the global developments, transformation towards market mechanism. The dominion of the multi-national companies upon the movement of commodities and services and markets' openness which contribute in increasing financial flows volume towards countries. FDI contributes in transforming technology and assists in compensating (lie deficit in local savings; therefore it is considered a financing source for them and can connect countries with a global production net. Thus care has been focused on suitable policies to attract foreign direct investments which are considered an incentive for growth.
\end{abstract}

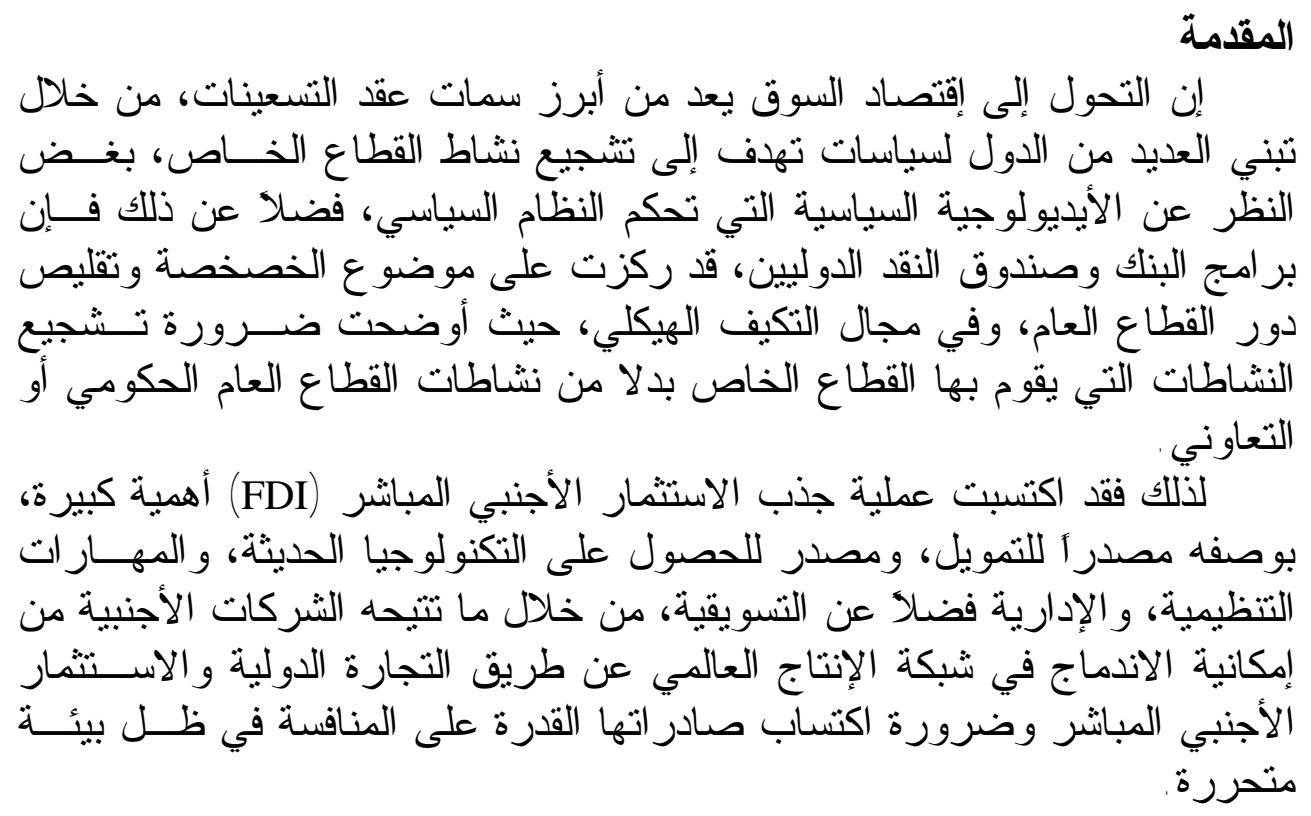




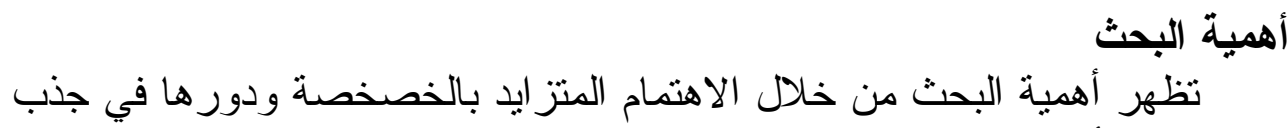

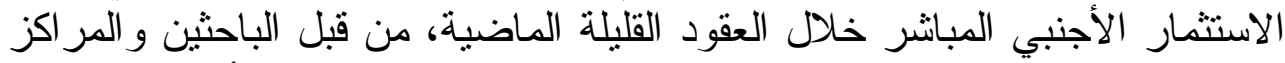

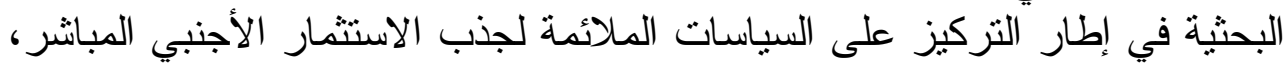

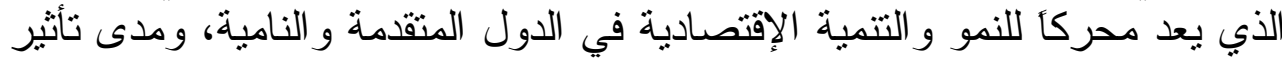

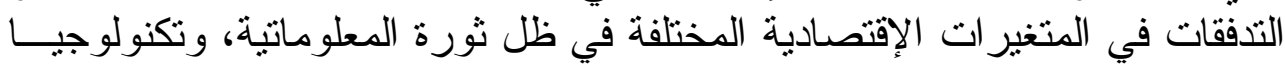

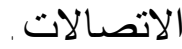

\section{مشكلة البحث}

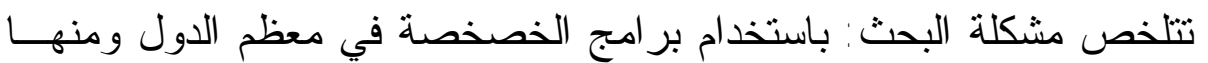

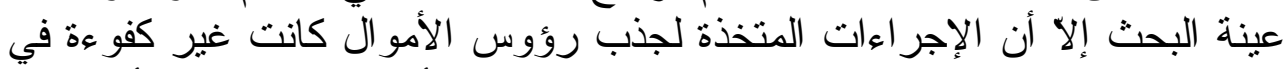

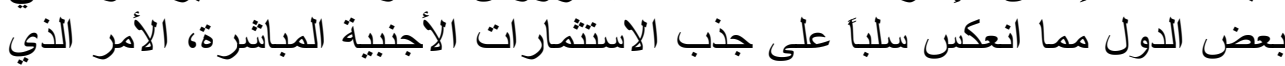
دعا إلى البحث في هذه المشكلة، ودر اسة أسبابها، و آفاقها المستقبلية.

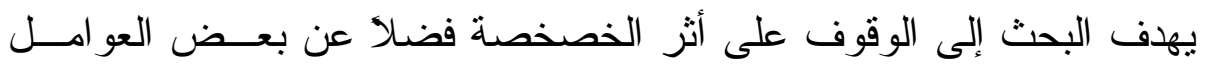

$$
\text { هدف البحث }
$$

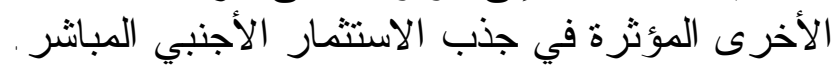

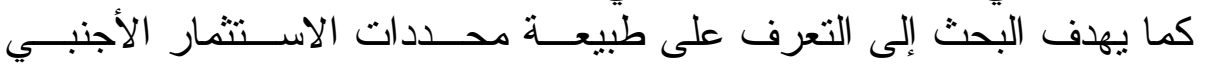

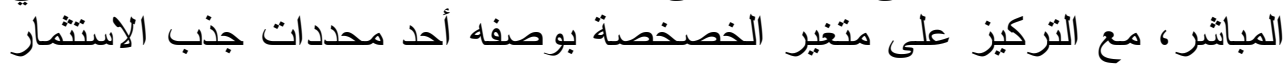

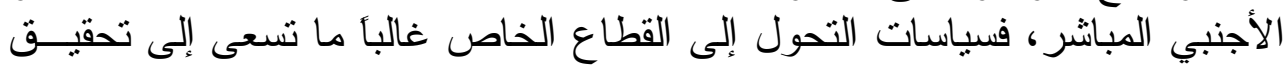

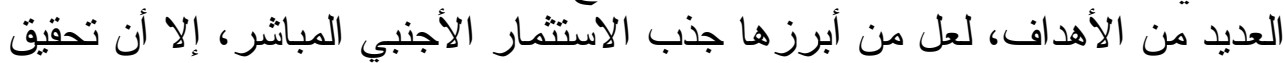

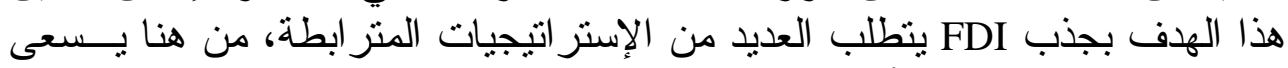

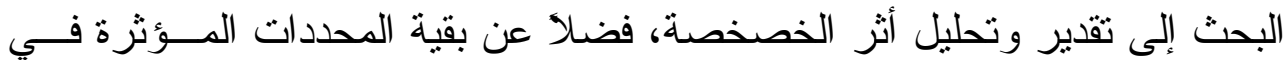

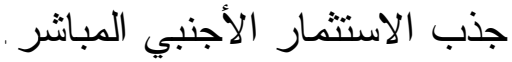

$$
\text { فرضية البحث البحث من فرضيتين أساسيتين: }
$$

1. تؤثر الخصخصة تأثير أيجابياً في جذب الاستثمار الأجنبي المباثر فـي دول العينة. 2. اختلاف درجة و أهمية كل محدد من محددات الاستثمار الأجنبي المباثر ، وتغير تلكك الأهمية بتغير البيئة الإقتصادية، فضلا عن تغير ها عبر الزمن.

\section{منهج البحث لمث}

سعيأ للوصول إلى اختبار فرضية البحث تم إجر اء در استة تطبيقيــة مقارنــــة

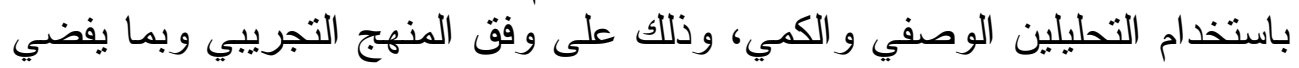


إلى تشخيص مقارن لإقتصاديات دول العينة، لإثبات أثر الخصخصة فـي جـذب الإبـ

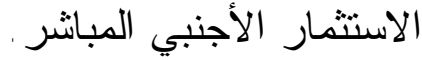

\section{العلاقة بين الخصخصة والاستثمار الأجنبي المباشر}

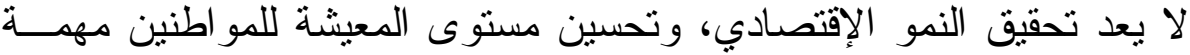

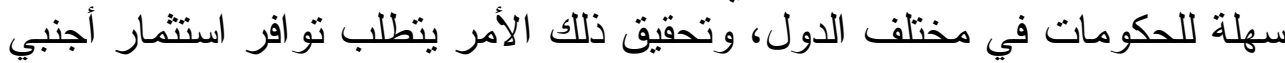

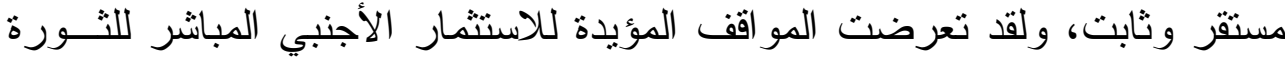

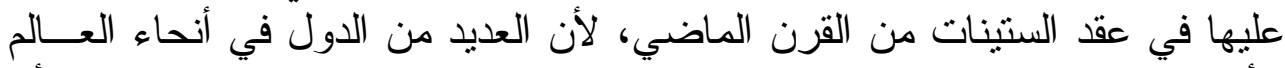

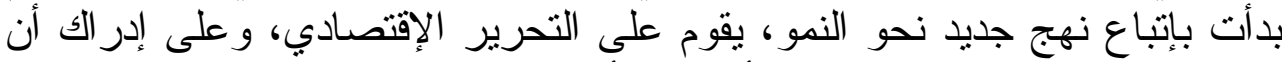

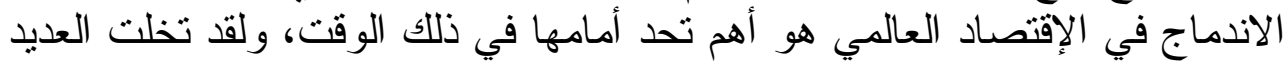

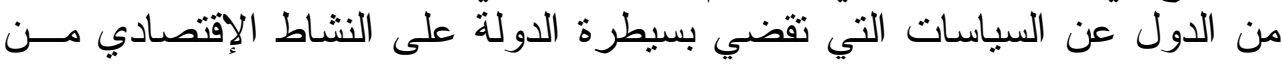

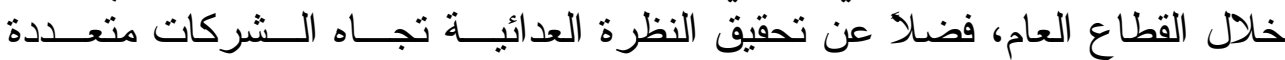

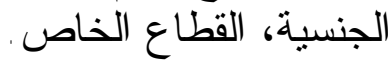
ويتتوع دور الاستثمار ات الأجنبية في هذا المجال، فهو إما أن يكون مباثـــرأ

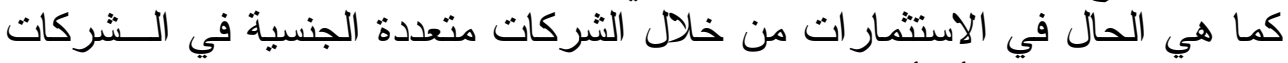

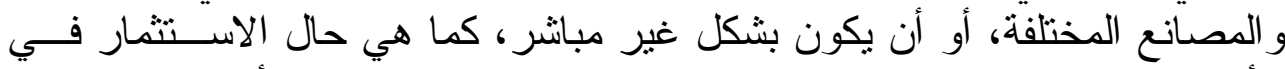

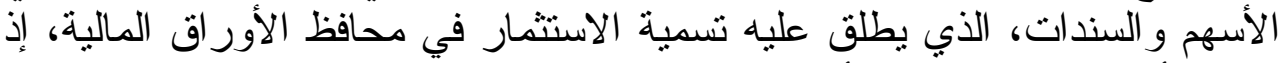

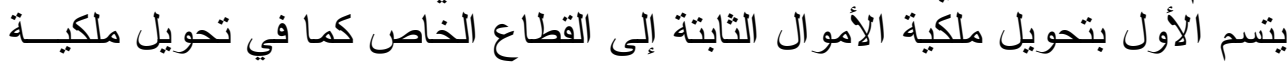

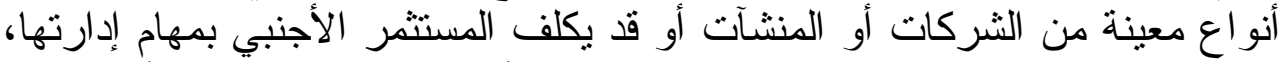

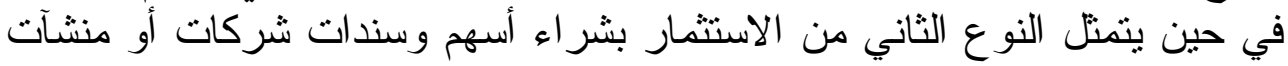
معينة (الاسكوا، 1996، 28 28).

وضمن هذا السياق عدت الخصخصة وفي العديد مــن دول العـالم وســـيلة

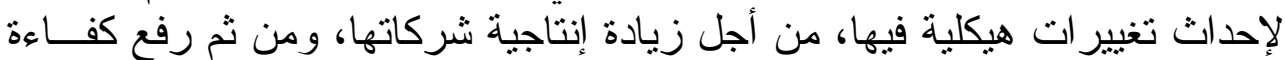

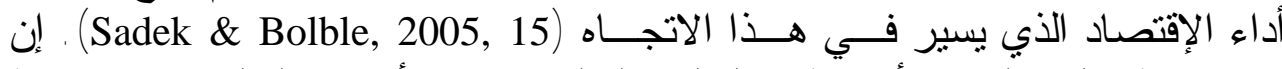

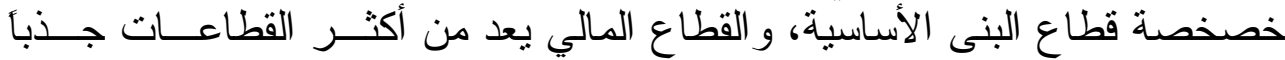

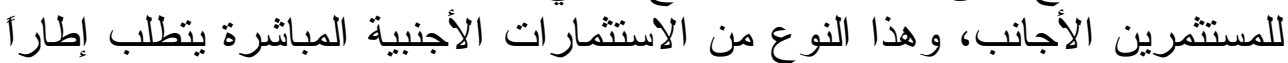

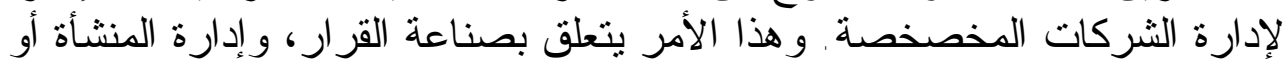

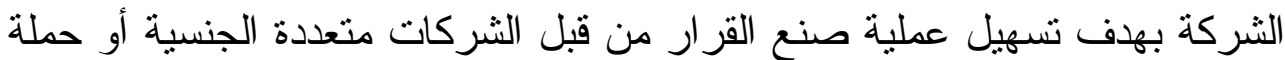

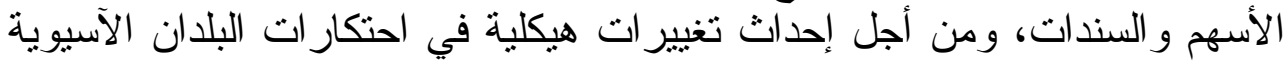

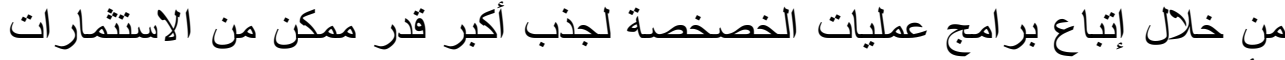

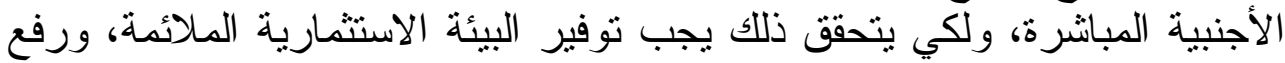

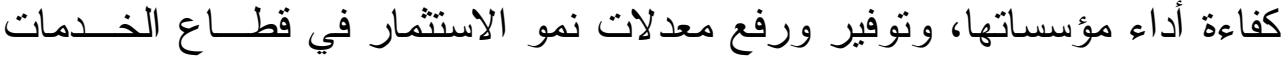

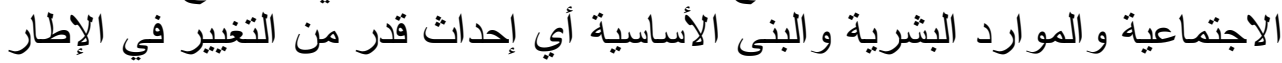

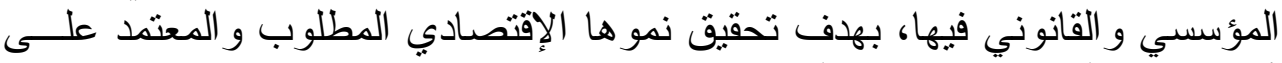
آلية السوق (ZHAN, 1993, 7) 


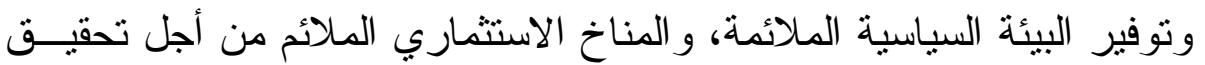

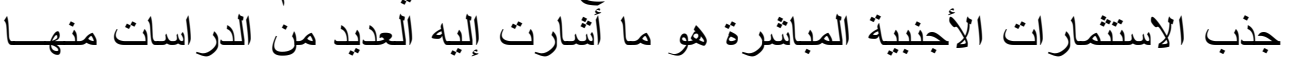

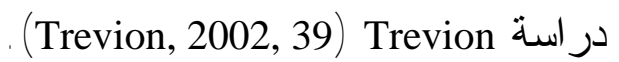

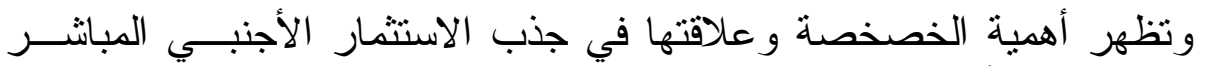

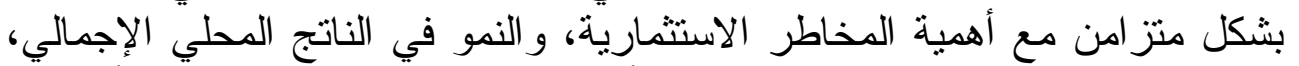

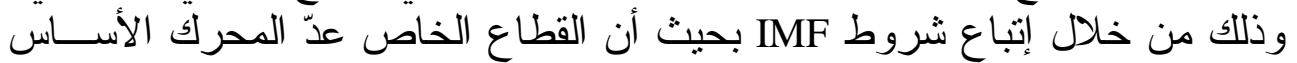

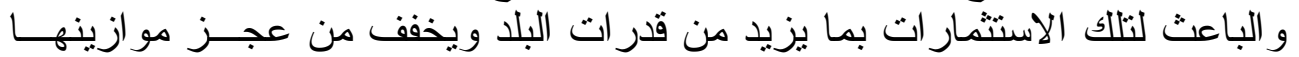
. (Nina and Bandelj, 2002, 25) وبالتالي الدور الإيجابي لتدفقات الاستثمار الأجنبي المباثر في الإقتـصادات

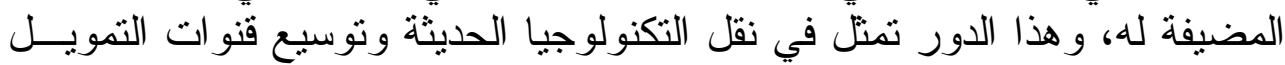

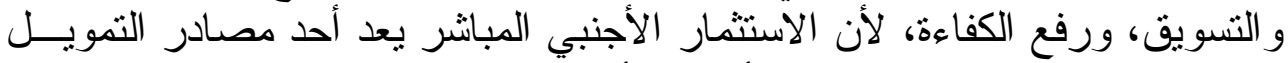

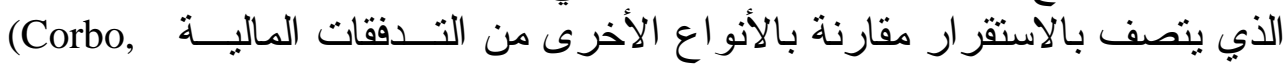
.1993, 226)

\section{عوامل جذب الاستثمارات الأجنبية المباشرة في ظل الخصخصة

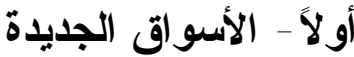

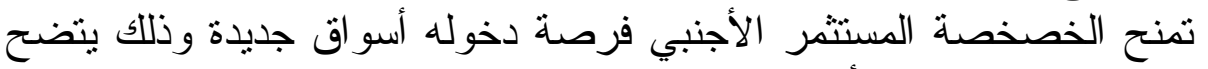

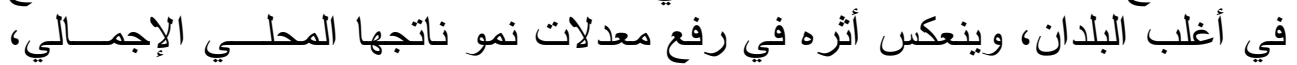

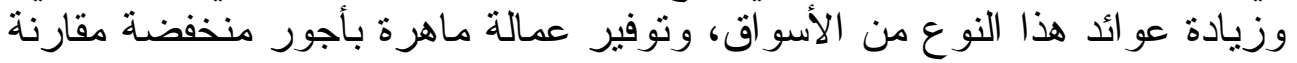

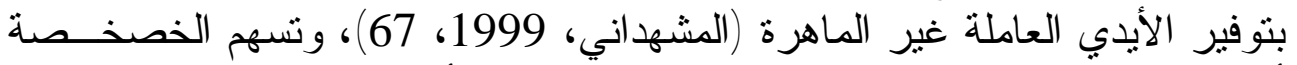

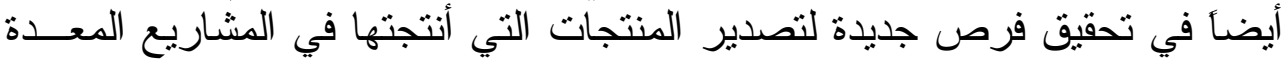

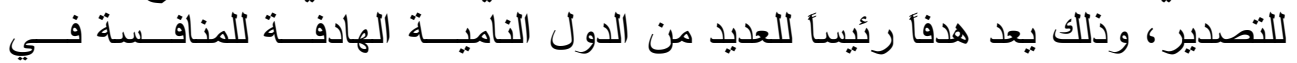

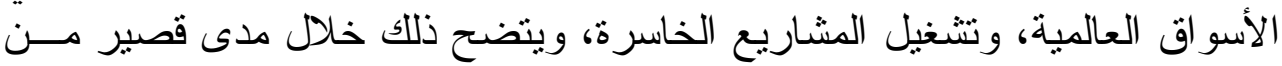

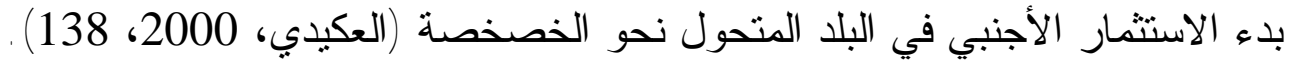

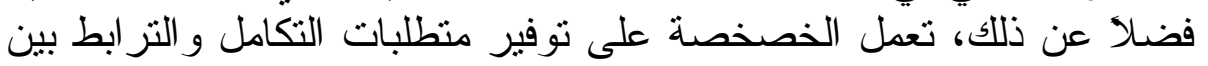

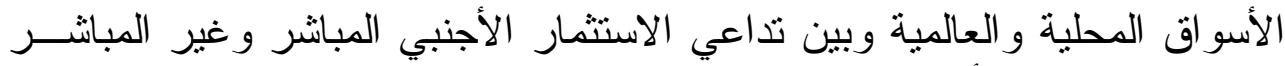

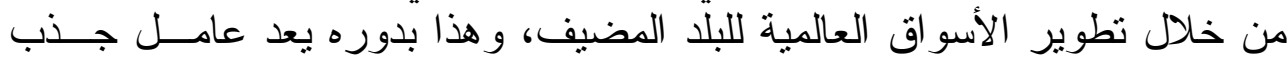

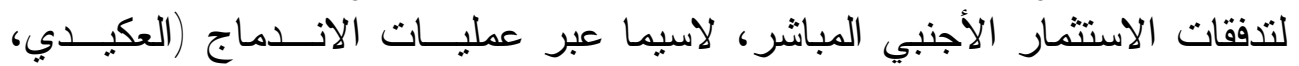

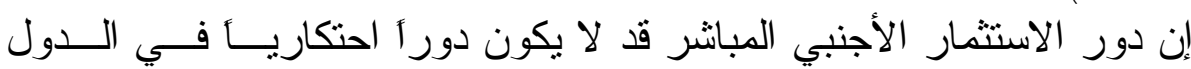

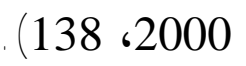

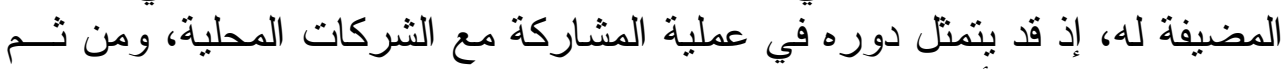

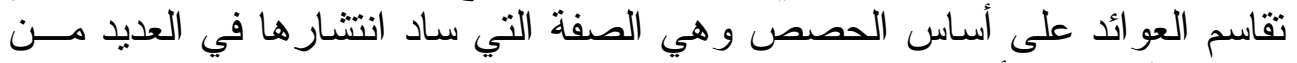

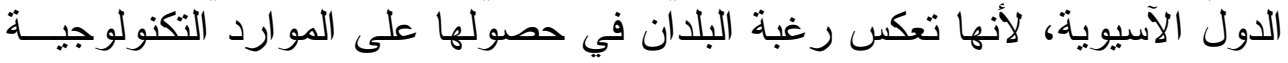

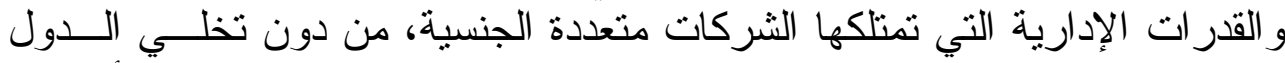

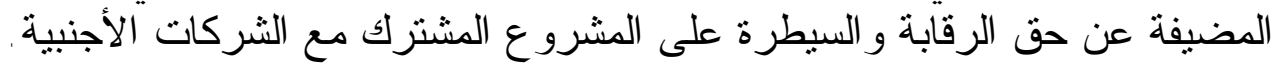




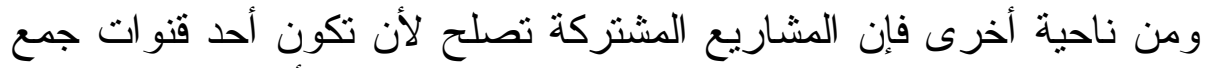

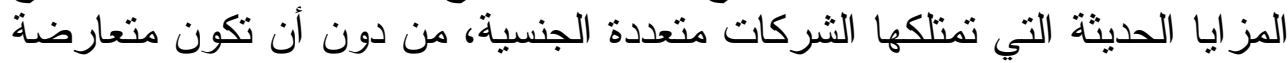

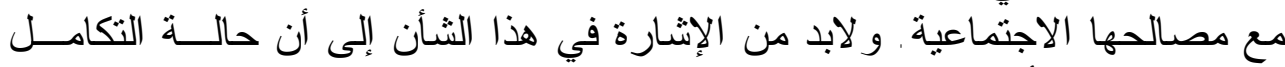

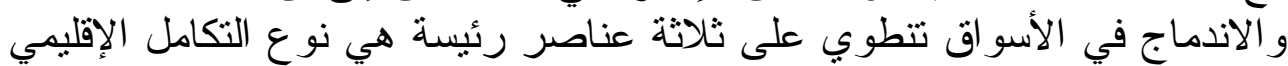

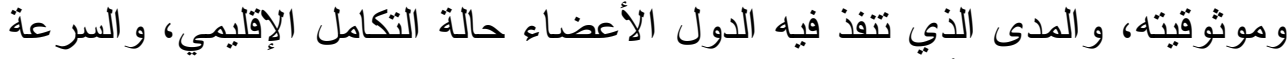

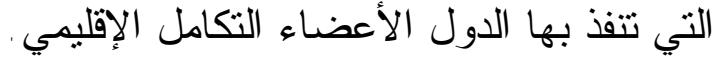

ثنانياً - قلة الدواجز أمام دخول الأسواق

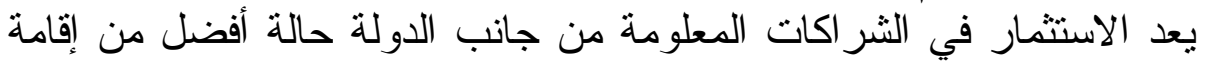

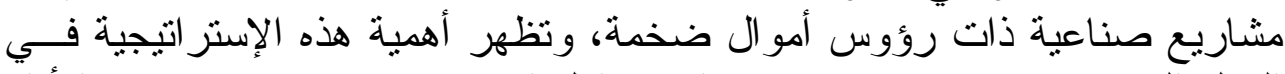

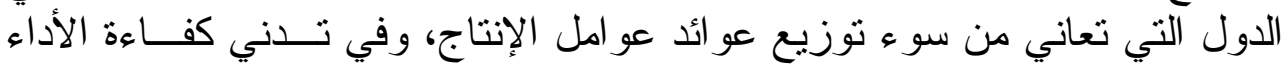

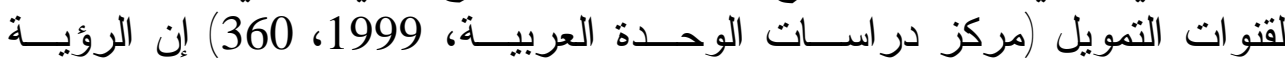

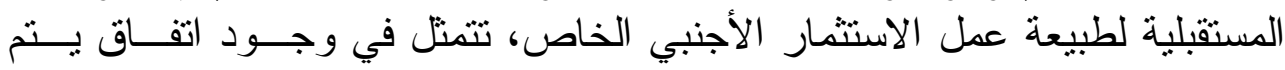

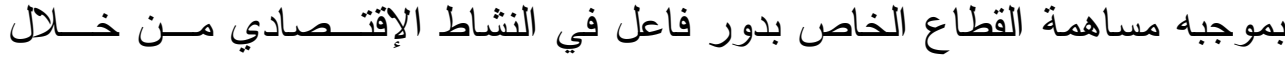

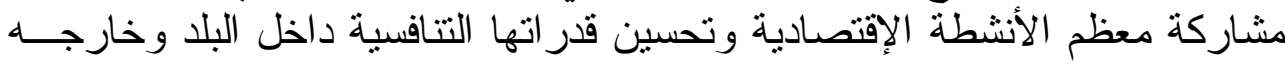

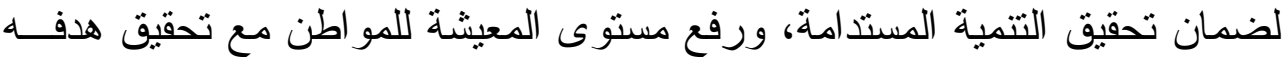

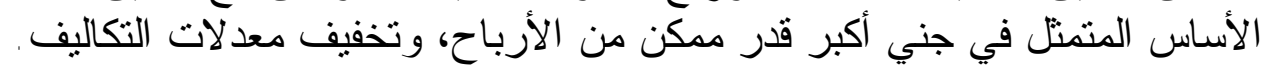

دوافع تدفق الاستثمار الأجنبي المباشر في ظل سياسة الخصخصة

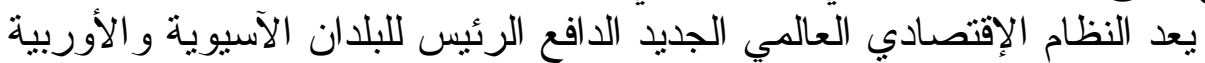

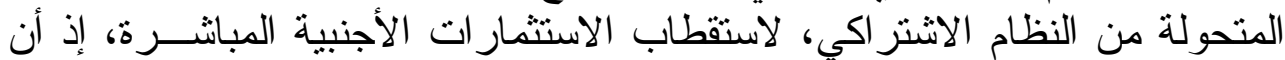

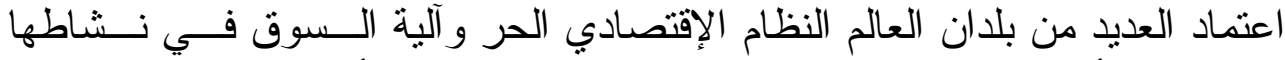

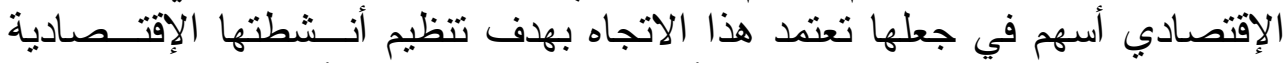

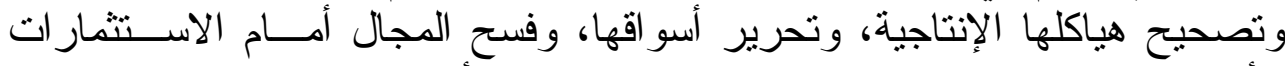

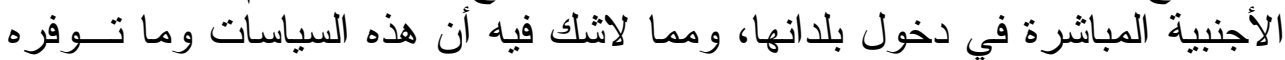

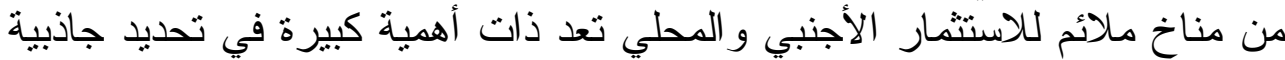

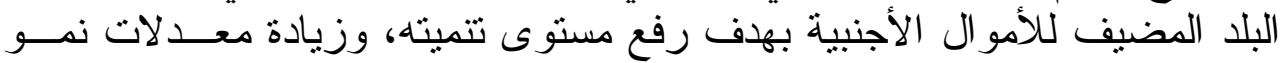

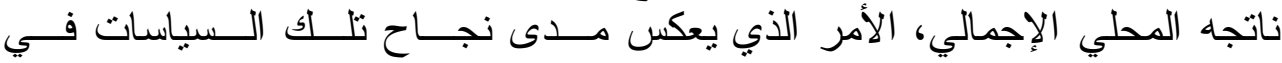

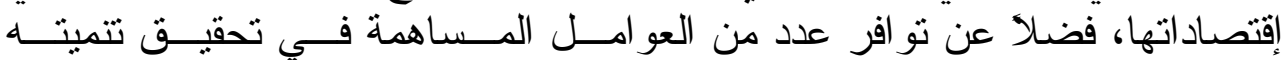

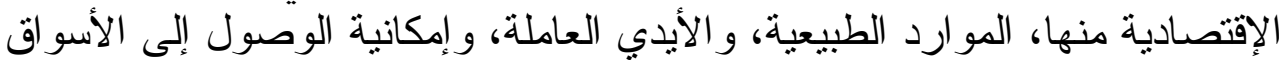

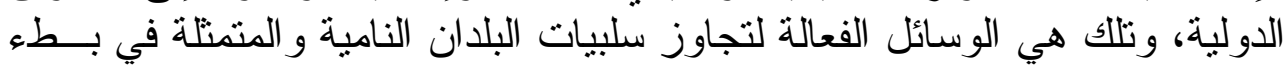

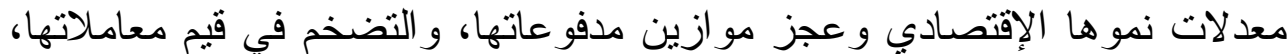

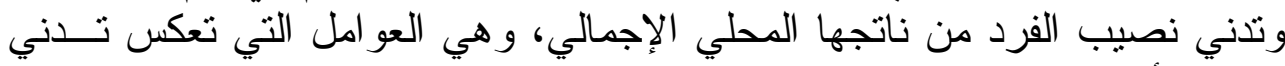

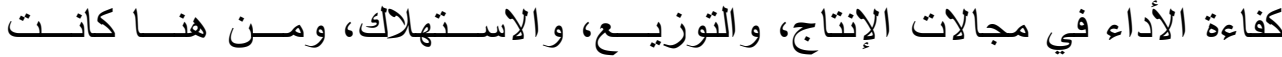

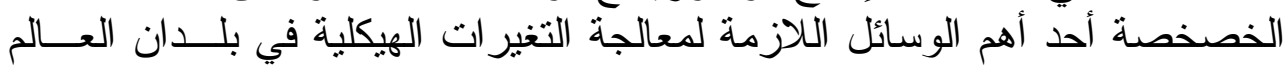




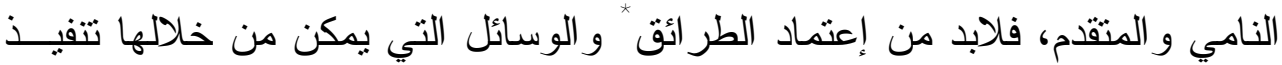

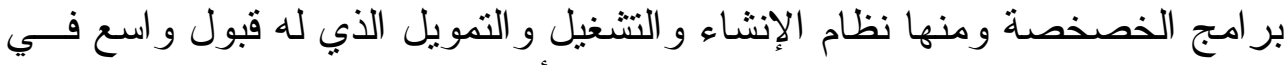

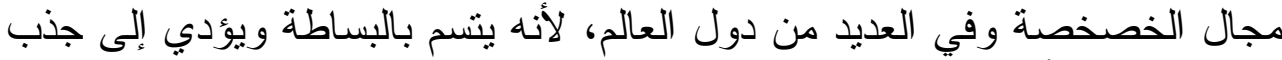

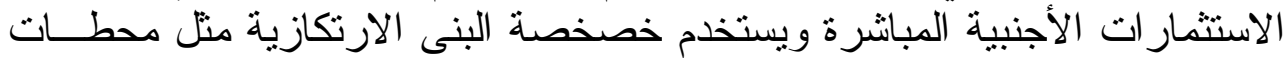

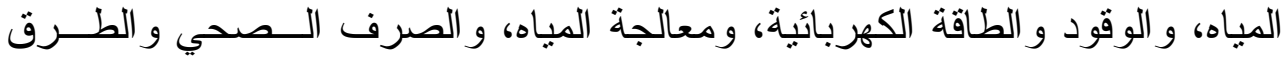

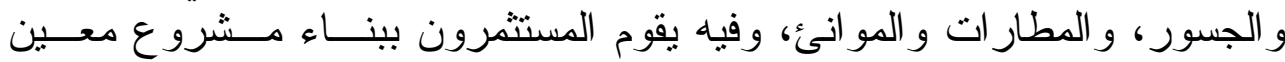

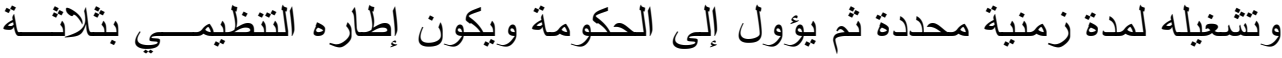

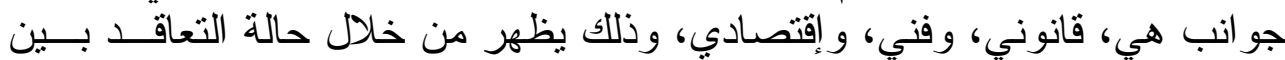

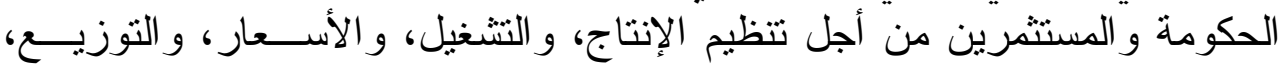

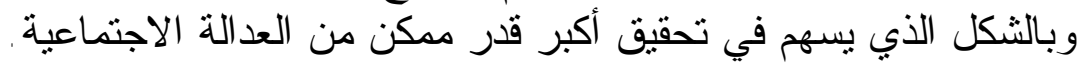

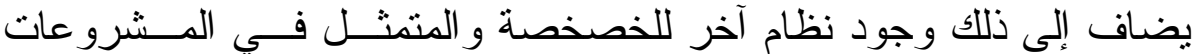

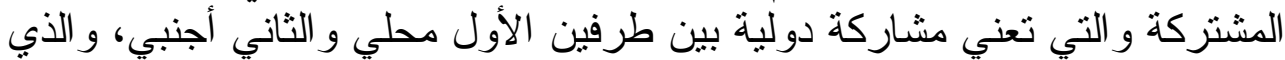

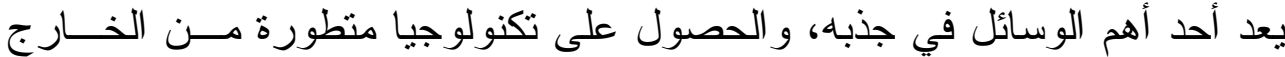

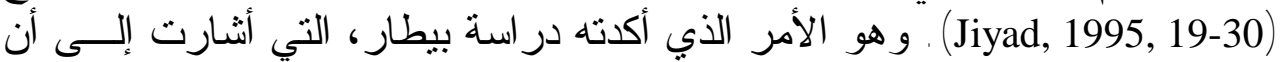

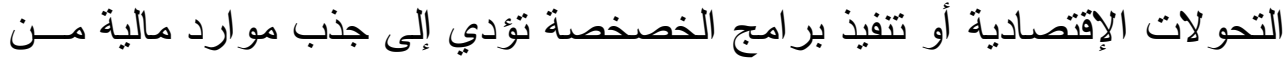

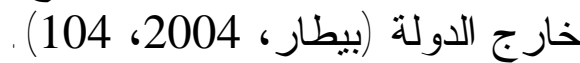

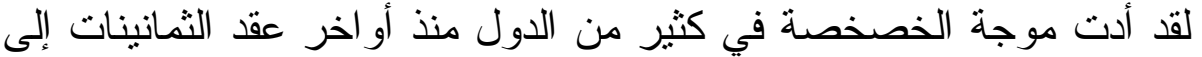

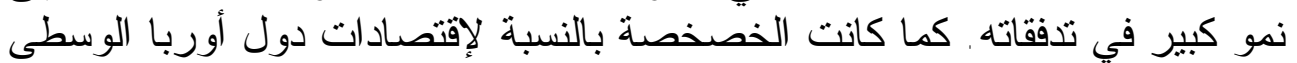

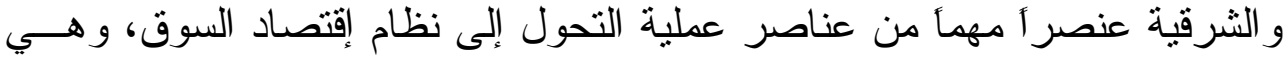

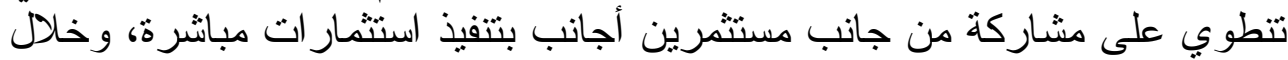

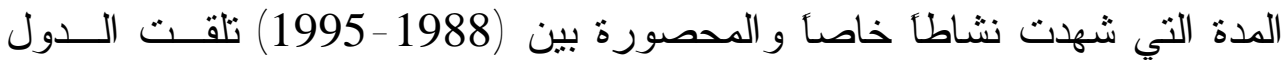

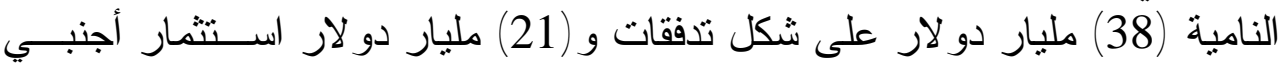

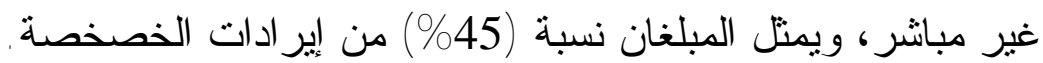

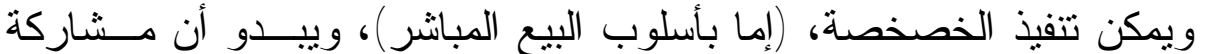

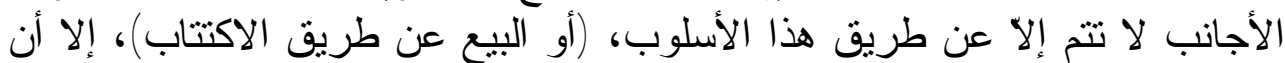

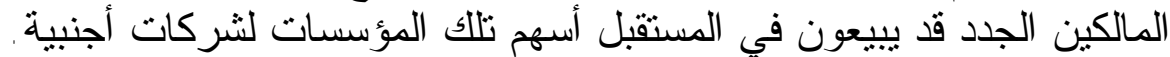

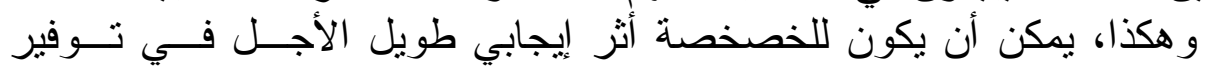

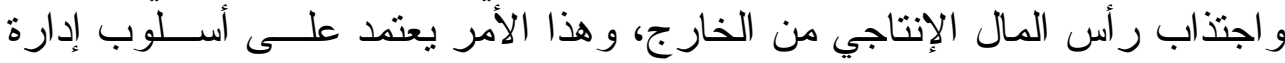

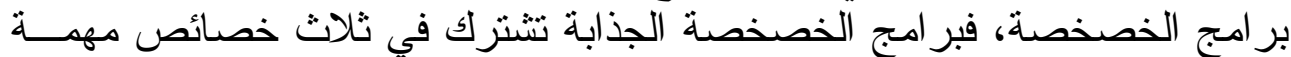

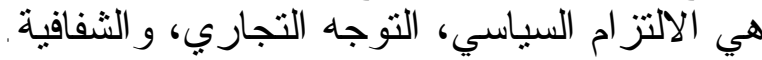

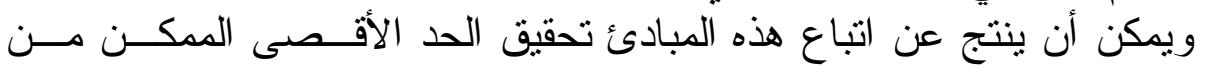

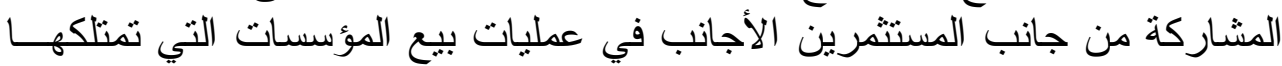

Coskun Can Aktan, Op.cit, PP. 13-50

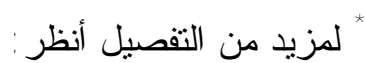

A comparative Approach in ESCWA Region, 1998. 


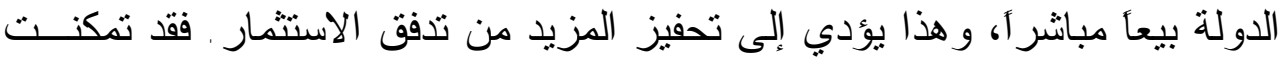

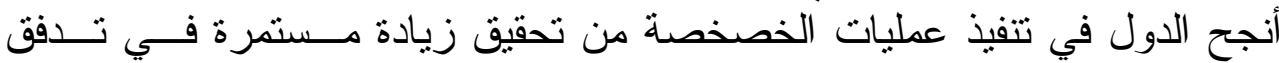

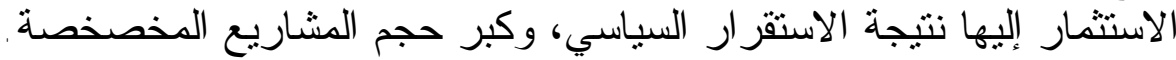

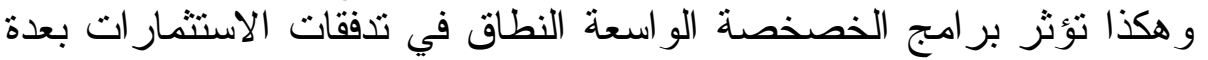

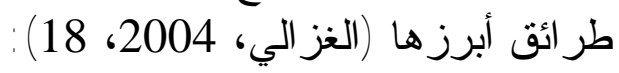

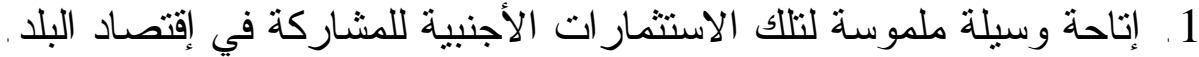

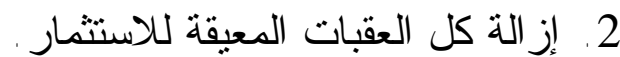

3. 3 أحسين البنية الأساسية.

4. إعطاء إنشارة للدولة لكي تتخذ الخطوات اللازمة لتهيئة بيئة ملائمة لاستثمار ات

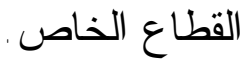

تحليل نتائج التقدير لأثز الخصخصة في جذب الاستثمار الأجنبي المباثــر لــدول العينة

ولغرض إثبات فرضية البحث التي تتص على الدور الإيجابي للخصخصة في

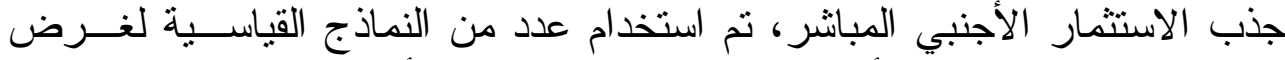

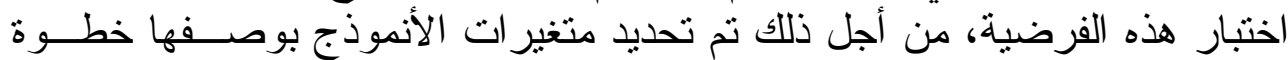

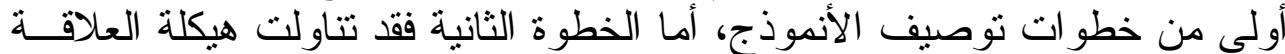

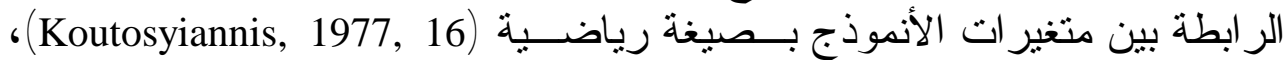

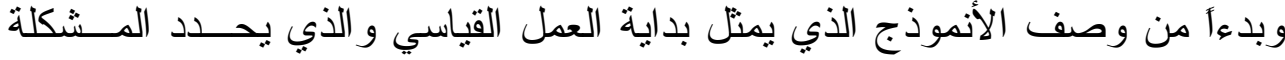

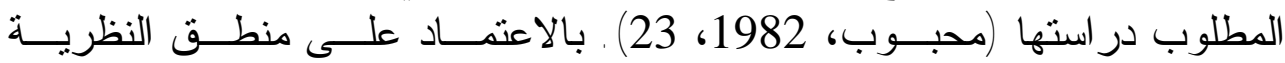

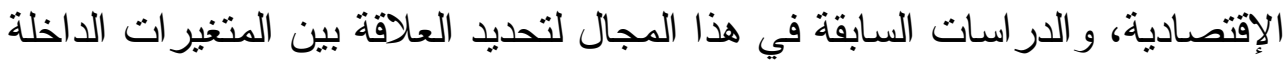

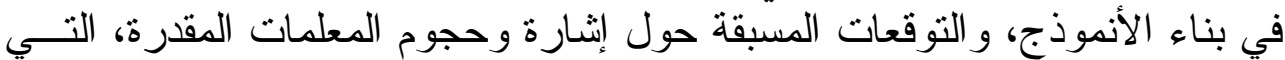
تعد بمثابة اختبار نظري يعتمد عليه في تقييم التقدير (Chang, 1984, 7-10).

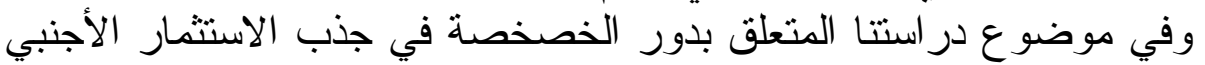

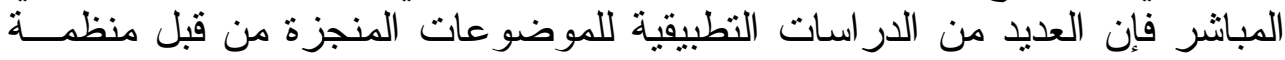

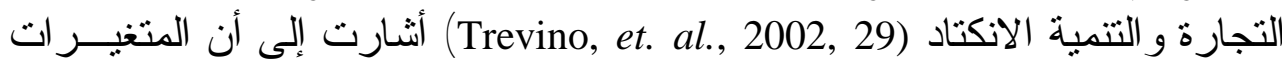

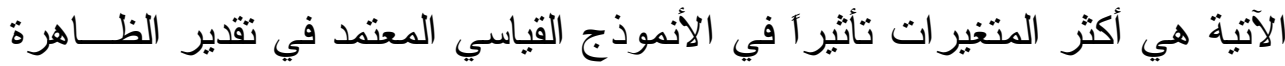

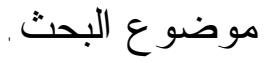

أولاً - المتفير المعتمد (Y) تم الاعتماد على قيم الاستثمار الأجنبي المباثشر بوصفه متغير أ معتـــأ فــي النماذج القياسية لدول العينة. ثانياً - المتغيرات المستقلة 


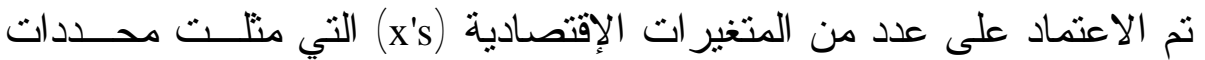
للاستثمار الأجنبي المباشر وكما يأتي (Trevino, et. al., 2002, 1-50):

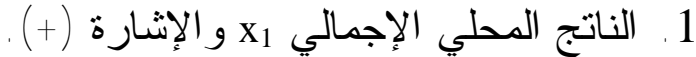

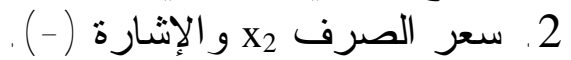

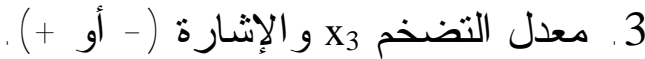

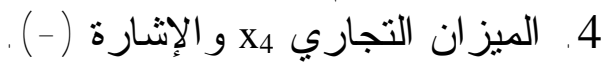

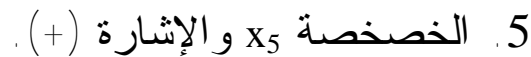

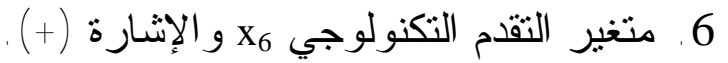

أولاً - تحليل نتائج تقدير الخصخصة في جذب الاستثمار الأجنبي المباشـر لـدول 1 ـ مجمو عة الدول الصناعية الكبرى وتم اختيار : أ. بريطانيا عن المجمو عة الأوربية. ب. باليابان عن المجموعة الآسيوية.

أ. بريطانيا

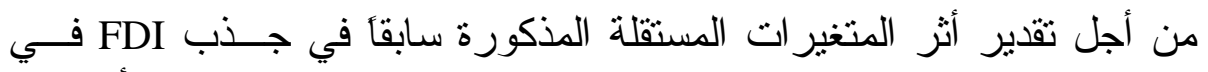

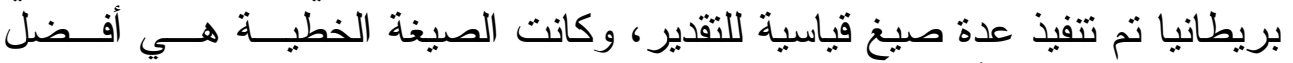
$\mathrm{Y}=-1089+650 \mathrm{x}_{2}-216 \mathrm{x}_{4}+205 \mathrm{x}_{5}+304 \mathrm{x}_{6}$

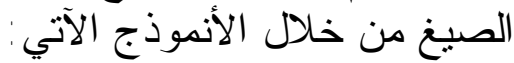
$\mathrm{t}^{*}=(-6.598)(6.503)-(1.708)(2.580)(2.866)$ $\mathrm{R}^{2}=92 \% \quad \mathrm{~F}=76.249 \quad \mathrm{D}-\mathrm{W}=2.166$

بلغت قيمة معامل سعر الصرف (650) (650) وحدة، وهذه القيمة تشير إلى أن

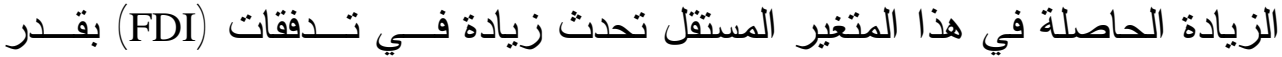

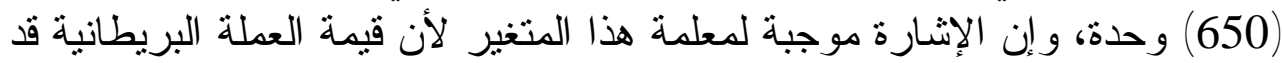

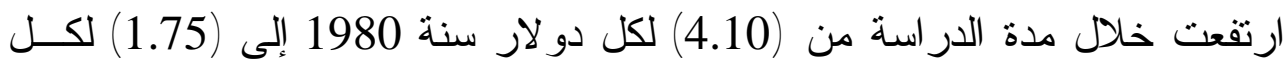

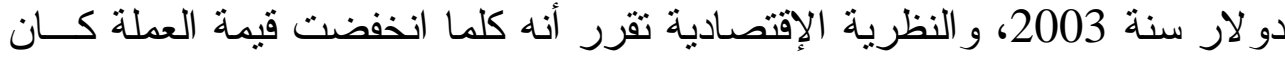

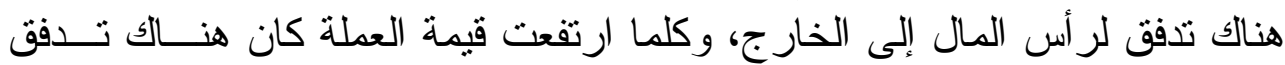

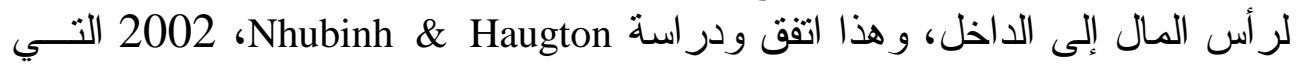

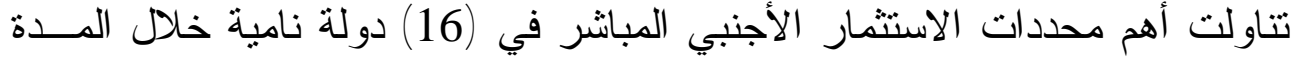

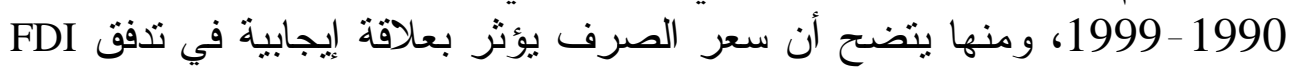

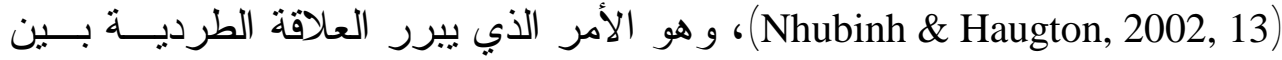

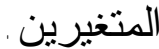
كما بلغت قيمة معامل الميز ان التجاري (x4) (216) وحدة، و هذه القيمة تعني بأن الانخفاض الحاصل في قيمة هذا المتغير تعود إلى زيادة في تدفق (FDI) بقدر

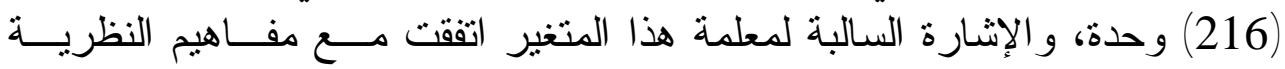




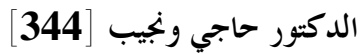

الإقتصادية، فضلا عن در اسة Frey \& Shinder، 1985 التي أوضحت بأن العجز

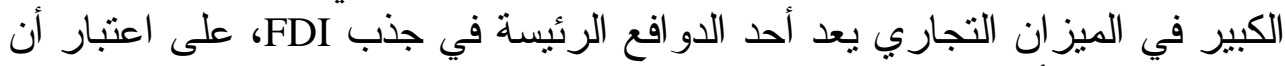

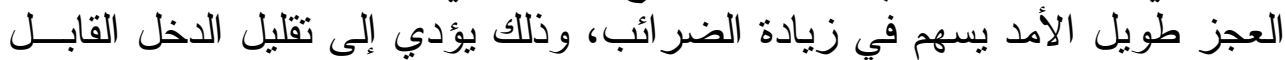

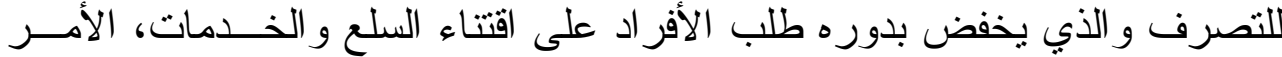

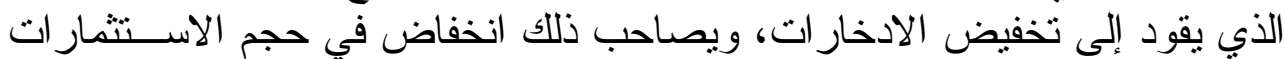

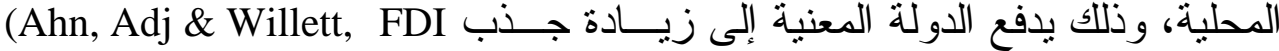

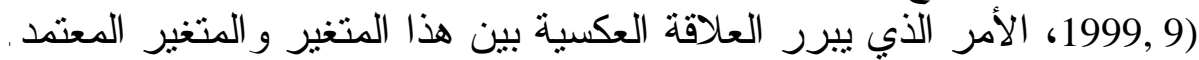

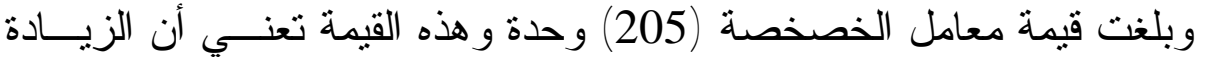

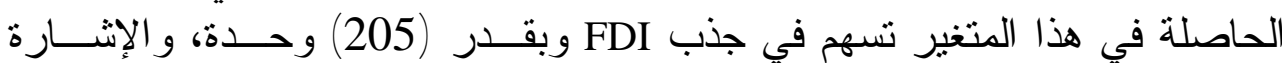

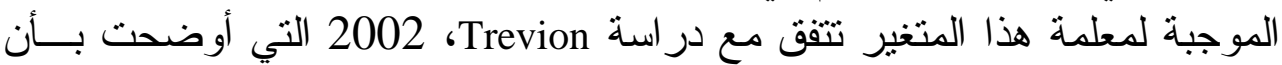

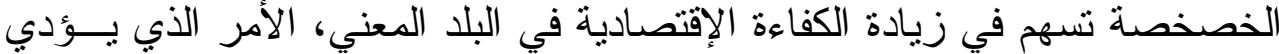

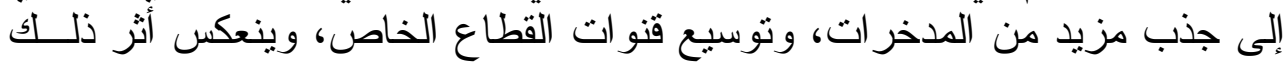

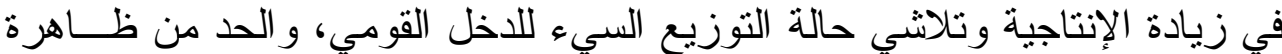

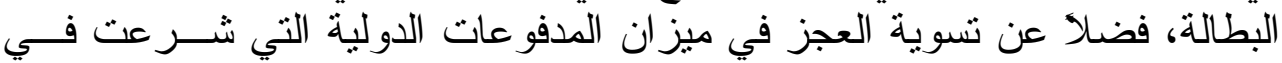
خصخصة إقتصادها (Trevion \& others, 2002, 29-39).

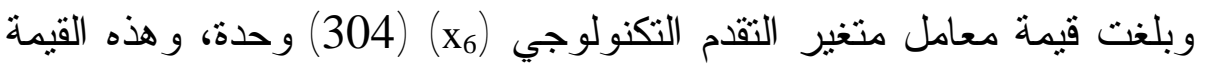

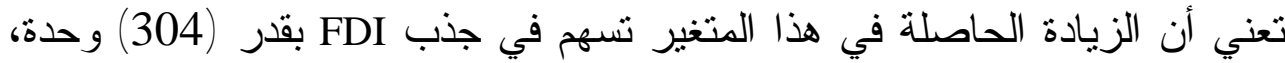

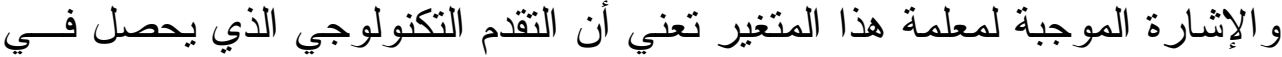

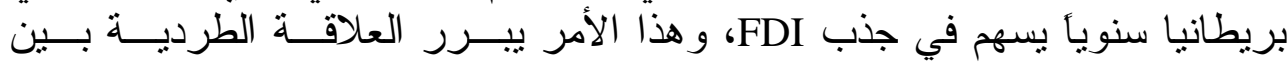
المتغيرين (العكيدي، 2000،

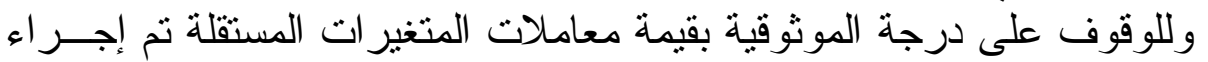

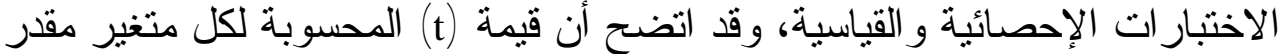

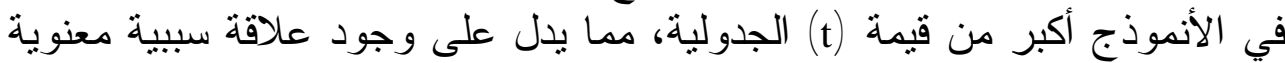

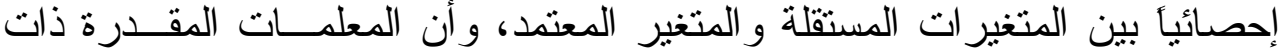

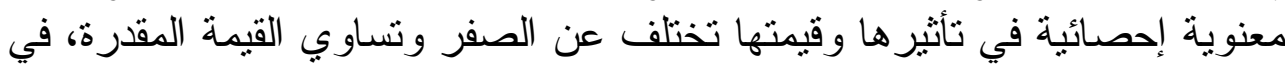

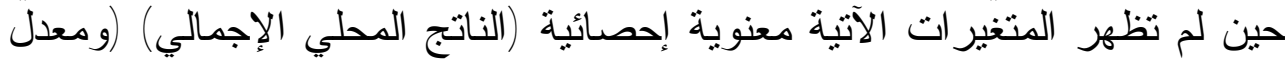

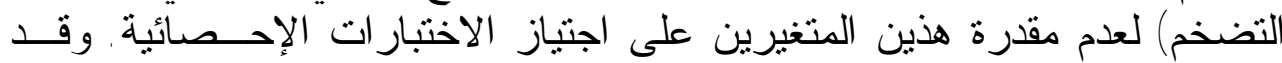

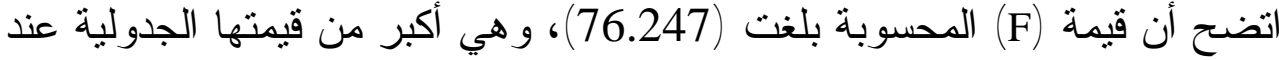

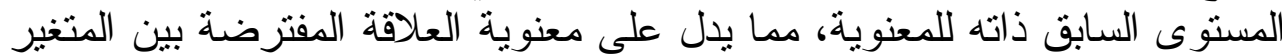

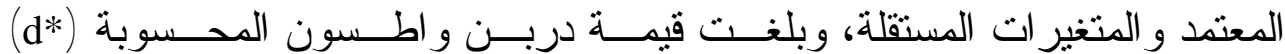

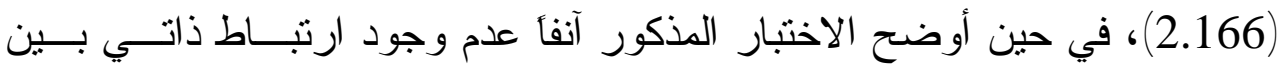

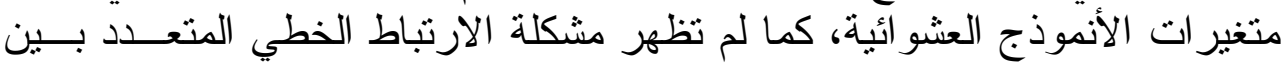

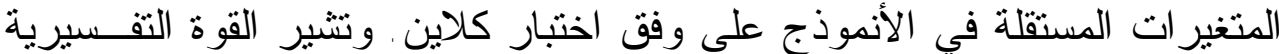

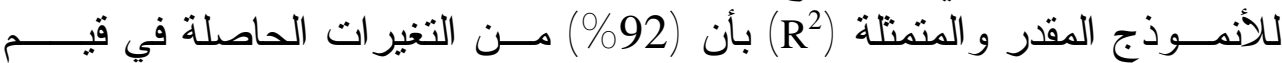

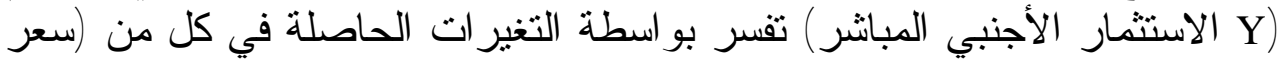




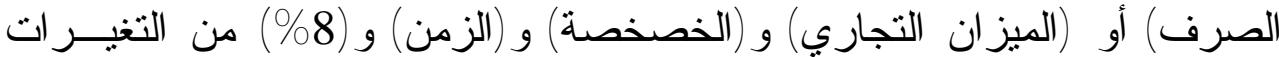

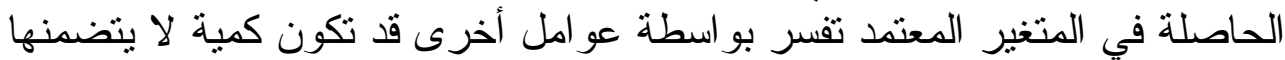
الأنموذج المقدر أو قد تكون نوعية.

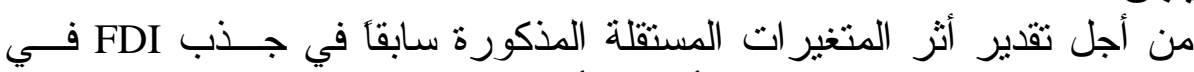

اليابان، اختيرت الصيغة الخطية التي أعطنتا أفضل النتائج غير المتحيزة الآتية: $\mathrm{Y}=25.188+487 \mathrm{x}_{4}+135 \mathrm{x}_{5}+508 \mathrm{x}_{6}$

$\mathrm{t}^{*}=(4.936)(4.744)(4.562)(1.704)$

$\mathrm{R}^{2}=90 \% \quad \mathrm{~F}=69.040 \quad \mathrm{D}-\mathrm{W}=1.193$

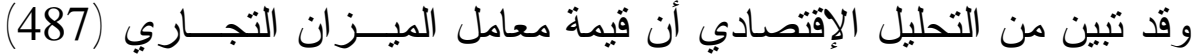

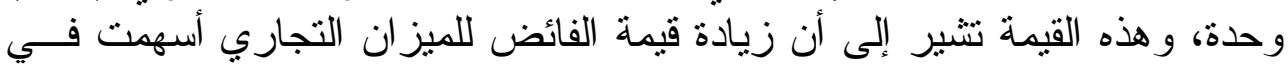

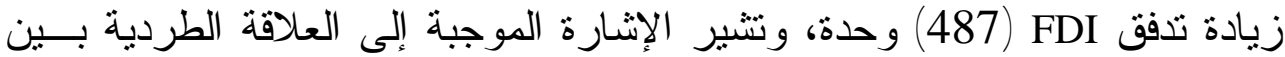

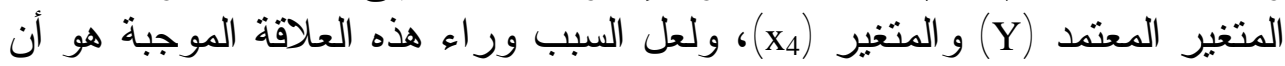

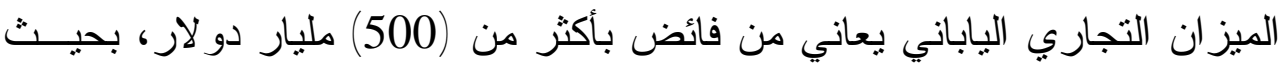

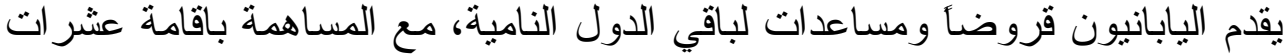

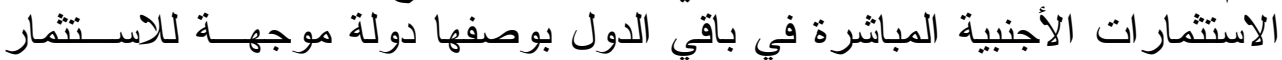

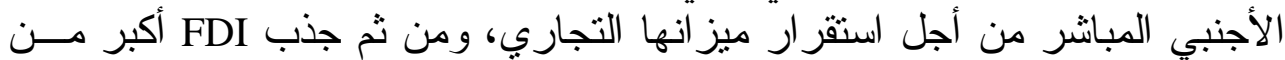

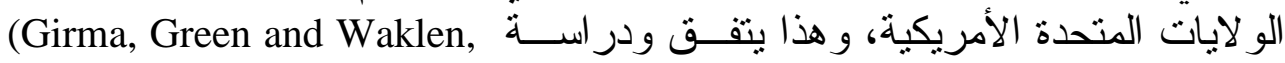
.1999, 14)

كما تبين أن قيمة معامل الخصخصة قد بلغت (135) وحدة، مــع الإثــارة

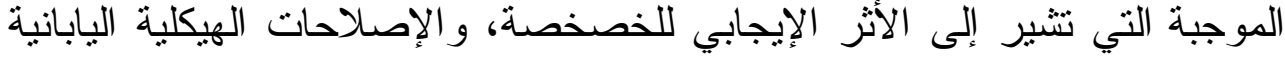

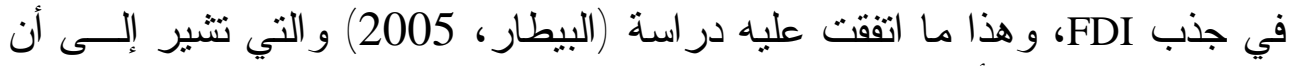

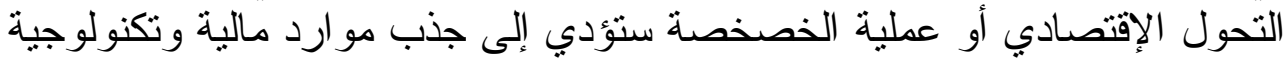

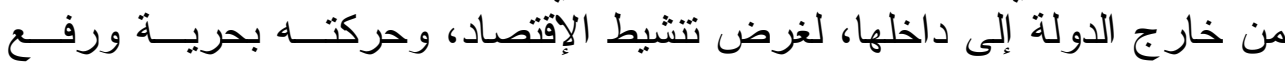

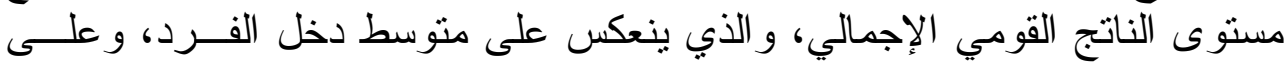

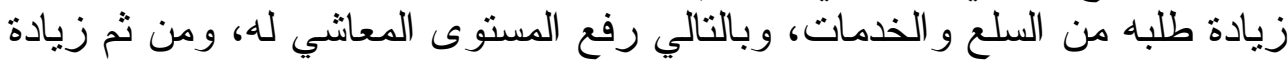
في الاستثمار الخاص المحلي الأجنبي. وبلئ

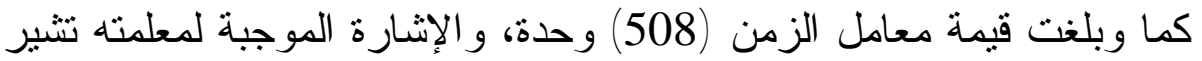

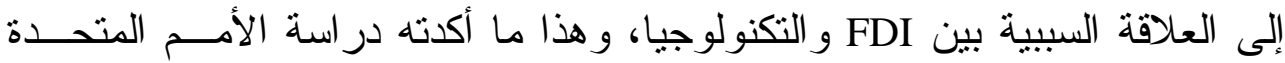

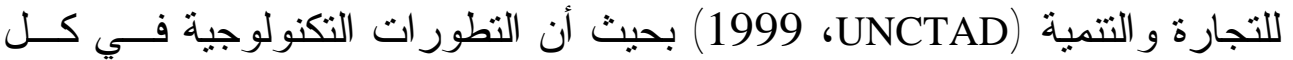

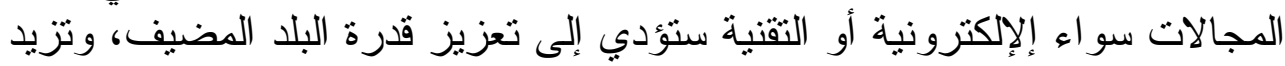

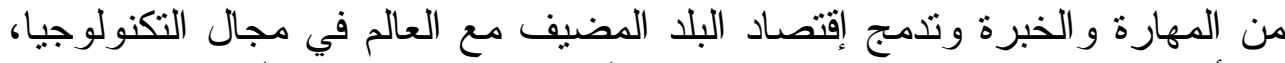
من أجل نسريع نمو الدول المضيفة النامية (UNCTAD, 1999,15).

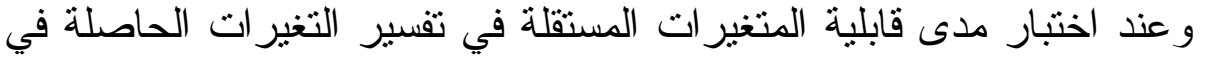
المتغير المعتمد إتضح وجود علاقة سببية معنوية إحصائية بين المتغير التيرل المستقلة، 


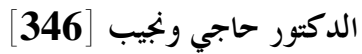

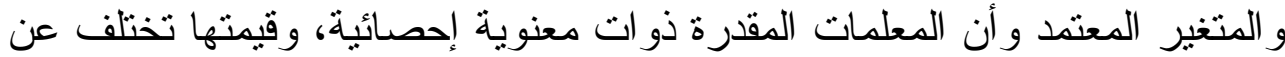

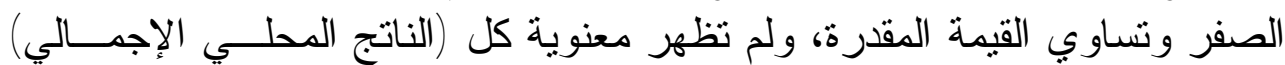

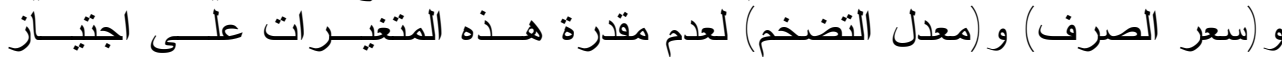

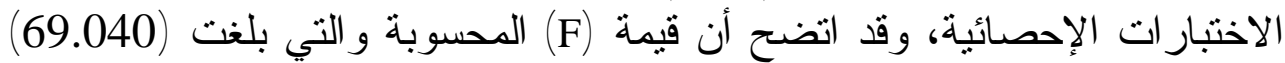

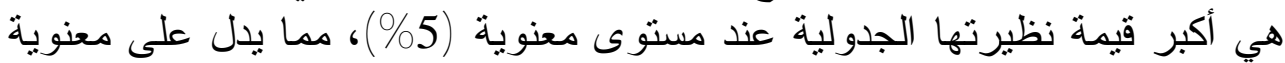

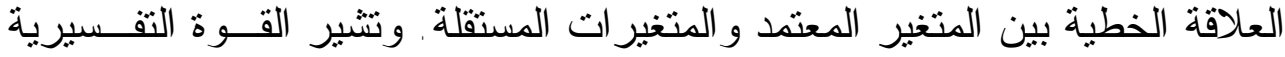

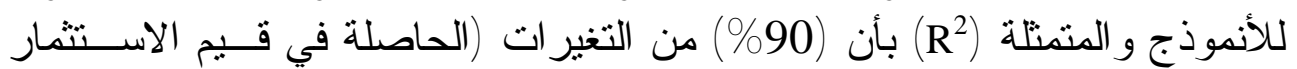

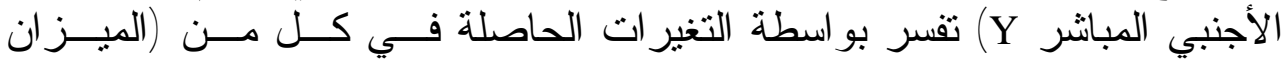

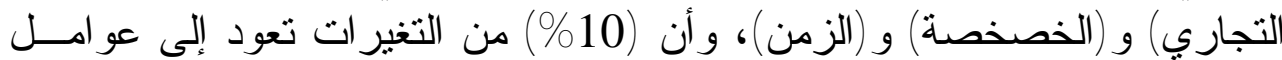

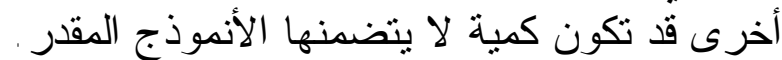

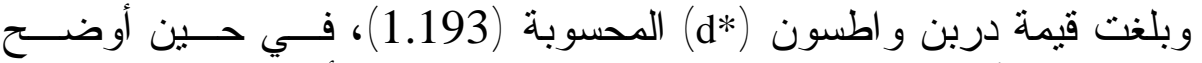

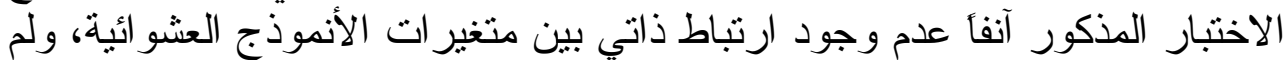

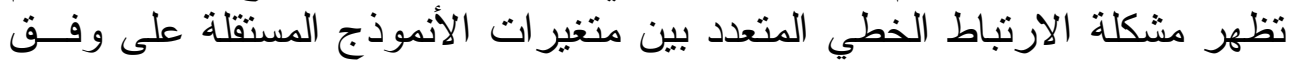

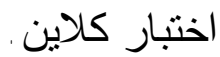

\section{2 2 مجموعة الدول الصناعية} أ. هنغاريا عن المجموعة الأوعة الأوربية. ب. سنغافورة عن المجموعة الآسيوية.

أ. هنغاريا

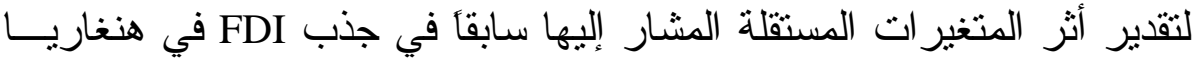

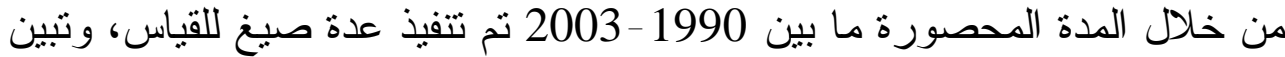
أن الصيغة شبه اللوغارتمية قد أعطت أفضل الصيغ من خلال الأنموذج الآتي:

$\log Y=626-313 \mathrm{x}_{2}+316 \mathrm{x}_{3}-273 \mathrm{x}_{4}+271 \mathrm{x}_{5}+600 \mathrm{x}_{6}$ $\mathrm{t}^{*}=(1.568)-(2.077)(3.763)-(2.126)(2.424)(2.755)$

$$
\mathrm{R}^{2}=87 \% \quad \mathrm{~F}=32.39 \quad \mathrm{D}-\mathrm{W}=2.77
$$

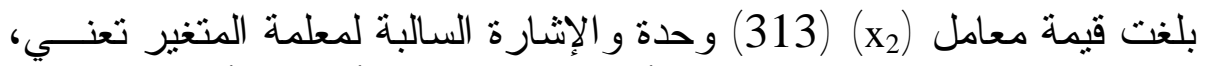

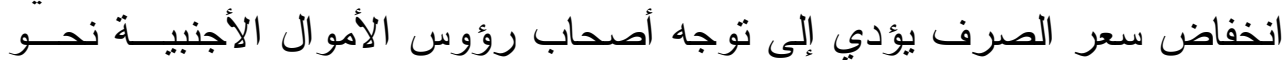

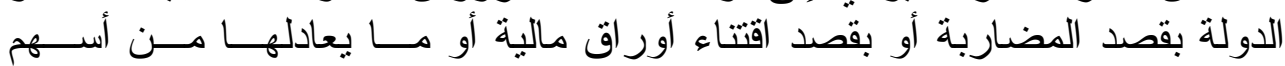

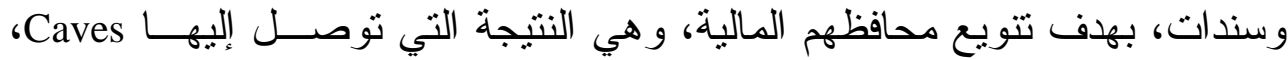

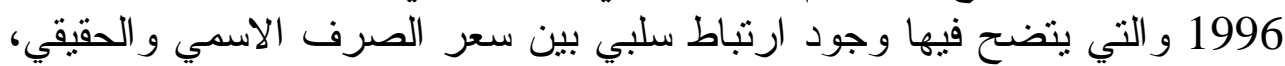

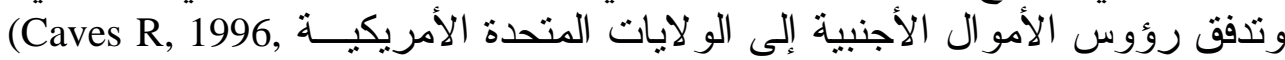

وبلغت قيمة معامل (x33) (316) وحدة، و الإثارة الموجبة لمعلمة هذا المتغير

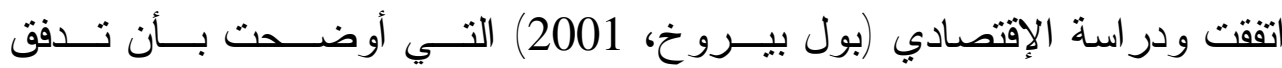


الاستثمار ات الأجنبية المباشرة، يؤدي إلى رفع معدلات التضخم و البطالة المتعلقــة

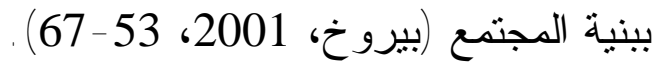

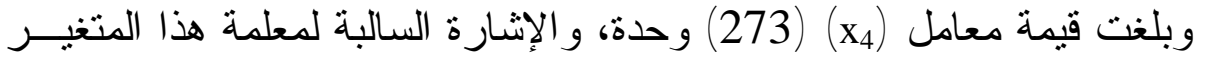

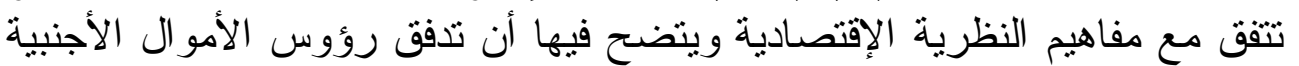

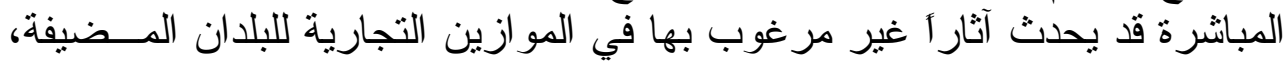

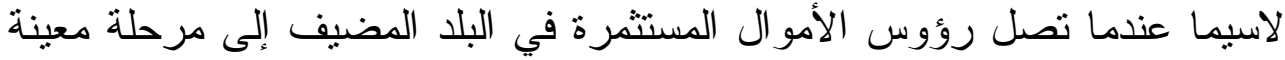

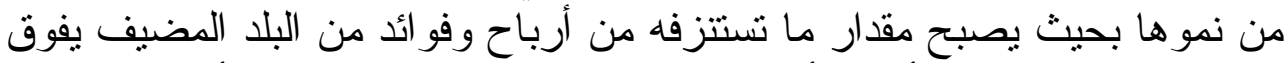

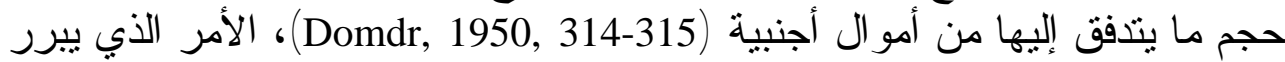

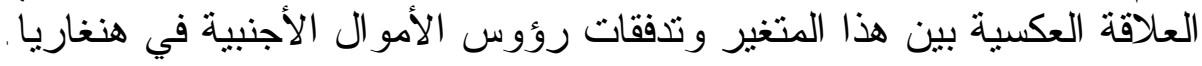

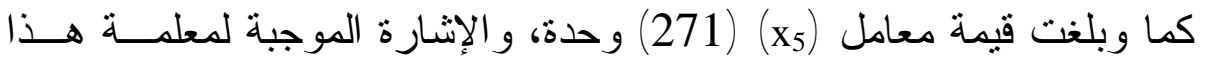

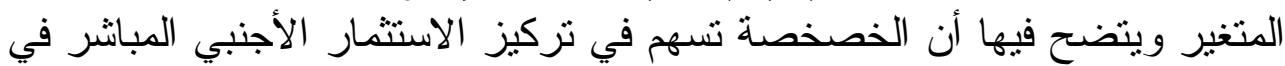

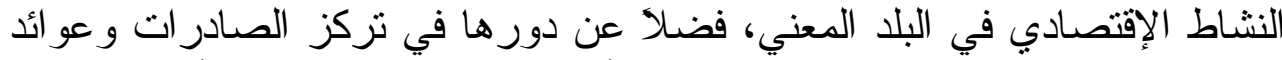

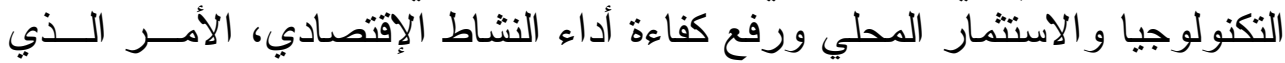

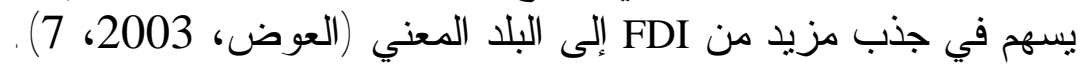

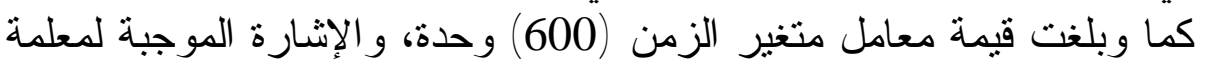

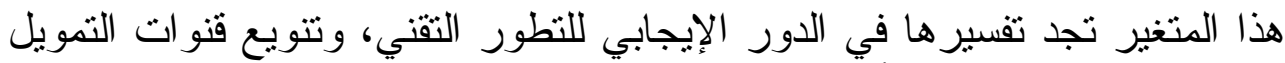

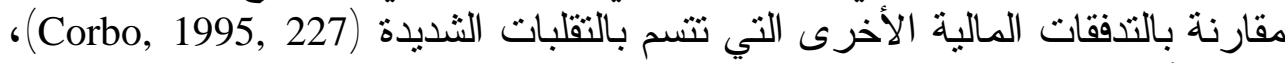

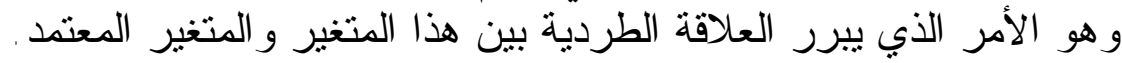

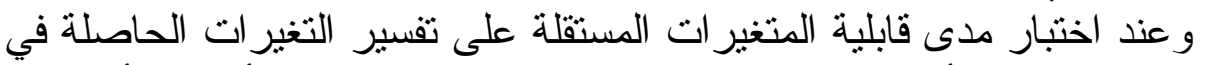

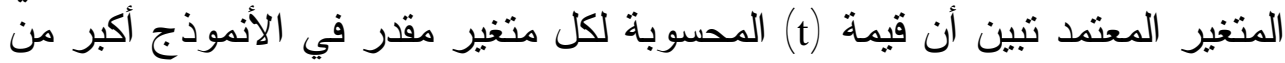

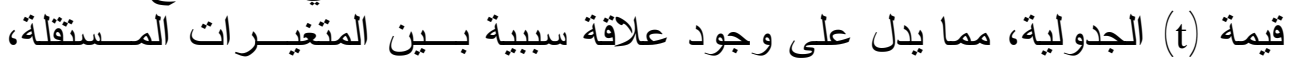

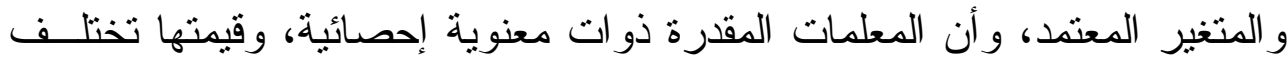

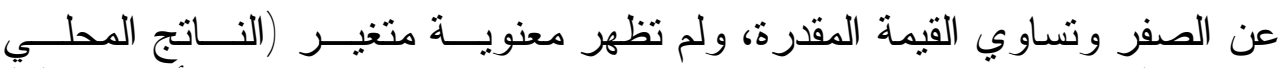

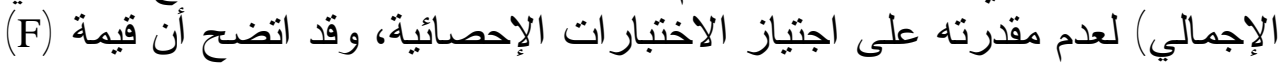

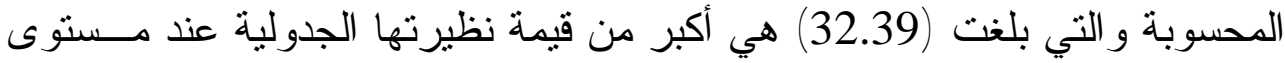

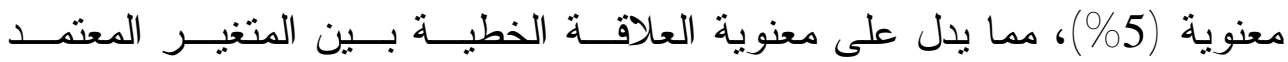
و المتغير ات المستقلة.

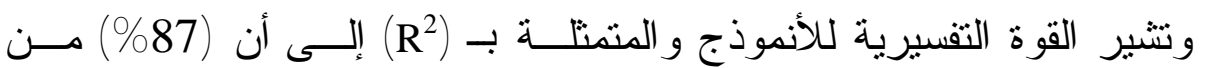

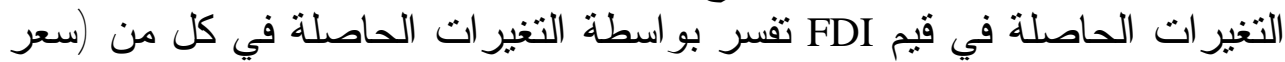

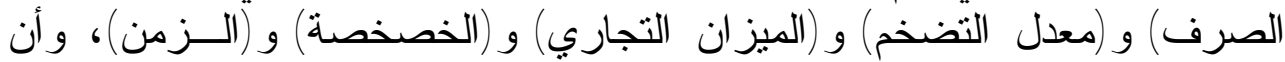

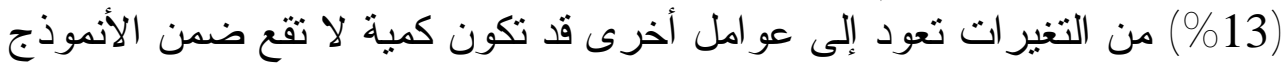

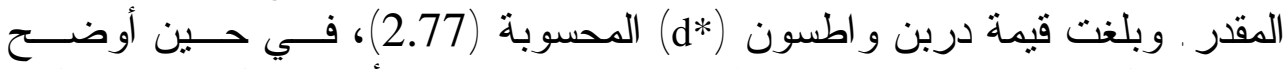

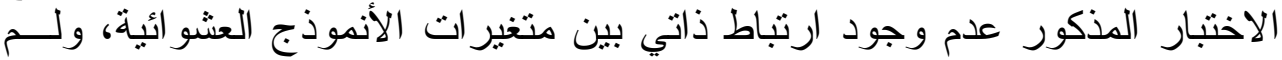

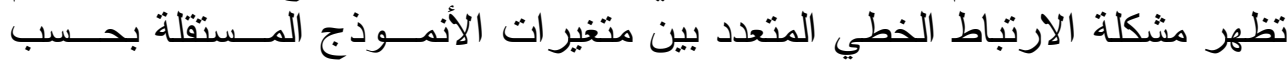

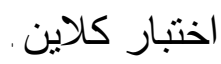




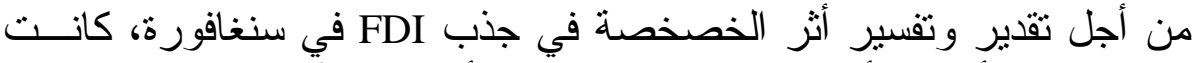

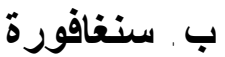
الصيغة الخطية قد أعطت أفضل النتائج على وفق الأنموذج الآتي:

$$
\begin{aligned}
& \mathrm{Y}=-10.876+52 \mathrm{x}_{2}+106 \mathrm{x}_{3}+174 \mathrm{x}_{4}+148 \mathrm{x}_{5}+766 \mathrm{x}_{6} \\
& \mathrm{t}^{*}=-(748)(2.564)(2.914)(2.548)(15.826) \\
& \mathrm{R}^{2}=99 \% \quad \mathrm{~F}=499.01 \quad \mathrm{D}-\mathrm{W}=2.393
\end{aligned}
$$

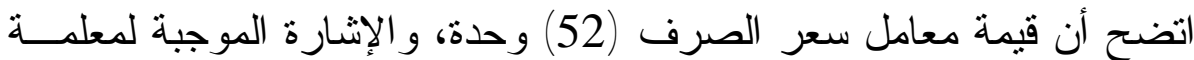

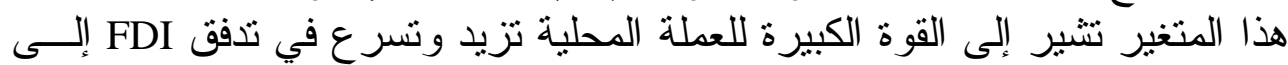

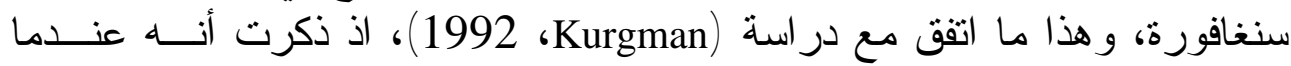

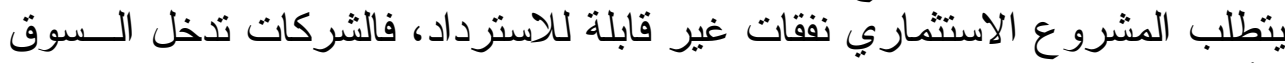

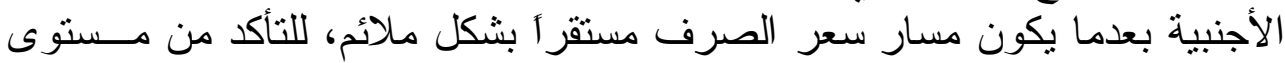
مقبول للأرباح (Kurgman and Graham, 1992,10).

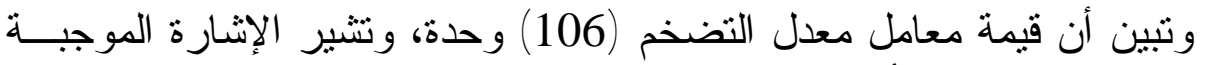

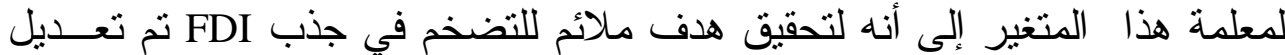

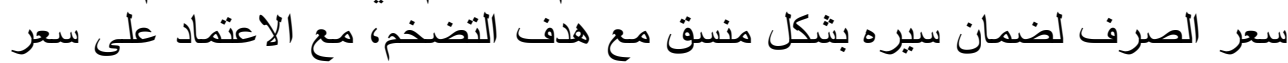

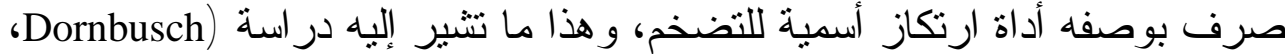

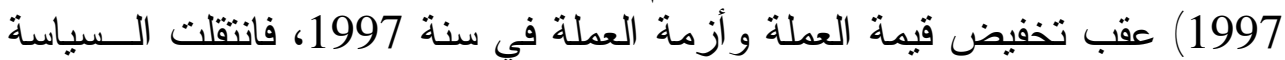

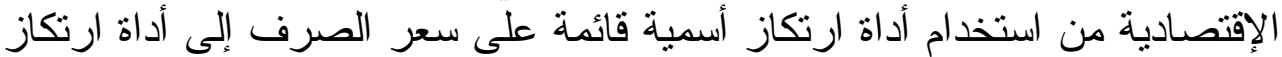

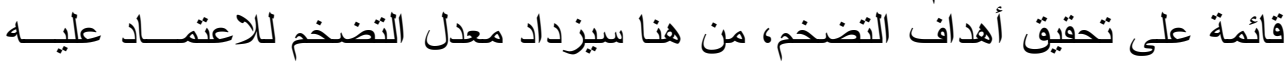

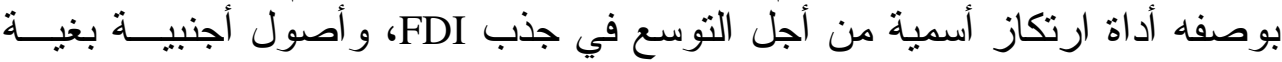

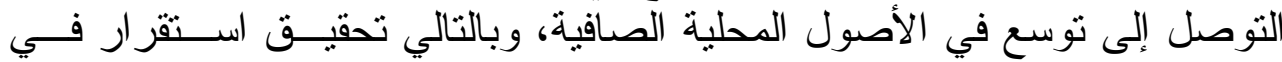

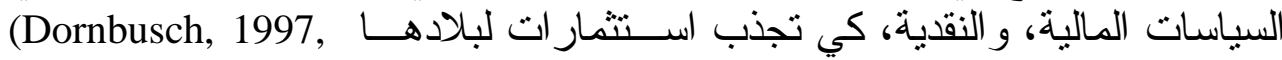

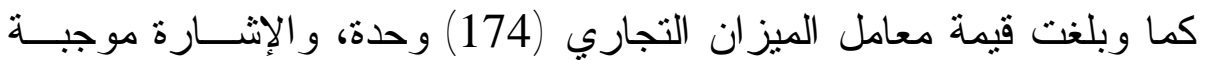
لمعلمة هذا المتغير ، ويتضح فيها النها لأنه تلجأ الثركات متعددة الجنسية إلى بيع عملاتها

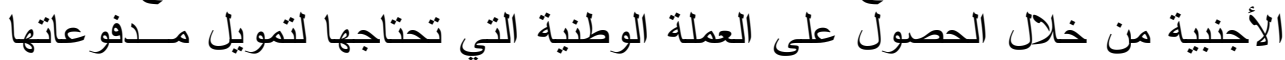

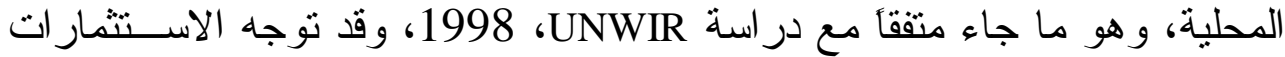

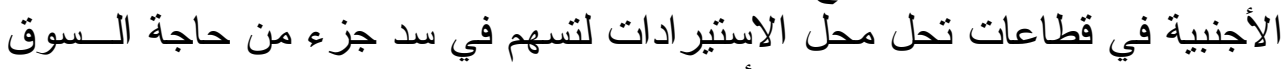

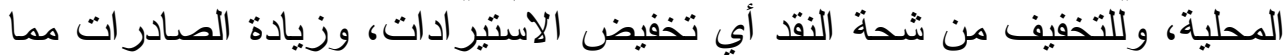

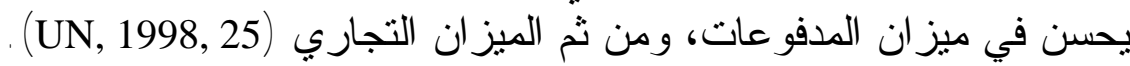

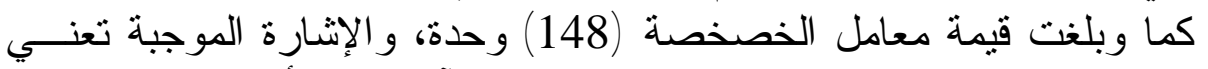

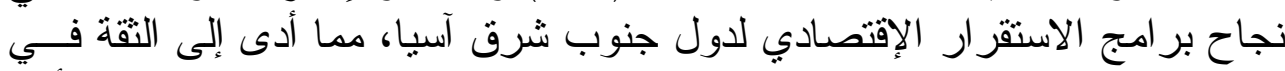

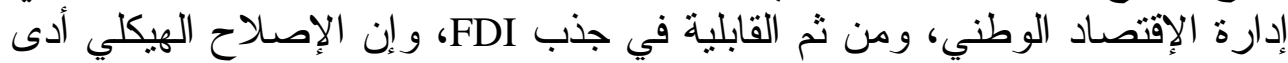

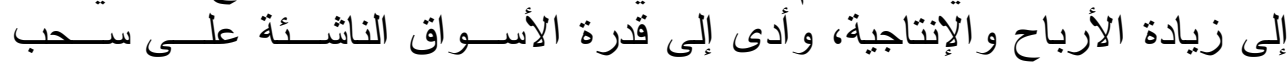


(Maria, المستثمرين الأجانب، وهذا ما أثنارت إليه دراسة (Ana Maria، (1999) .1999, 23)

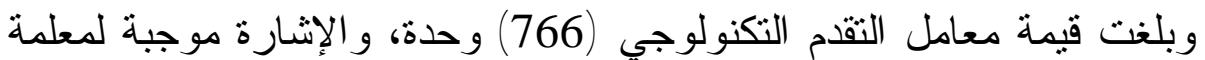

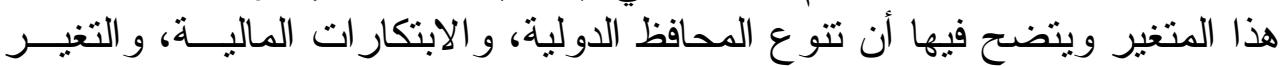

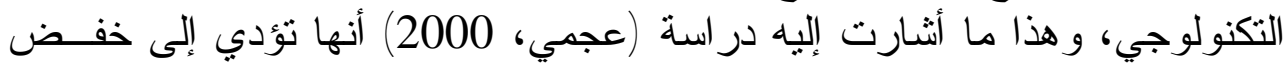

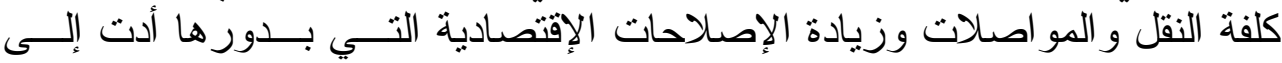

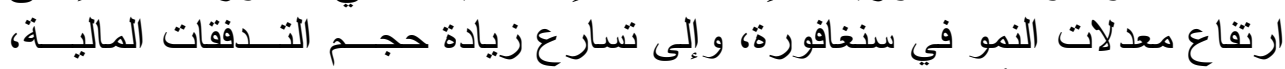

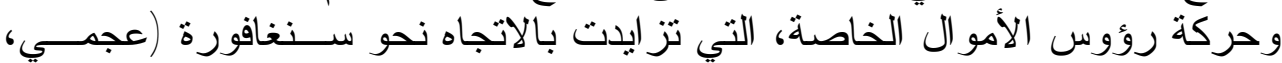

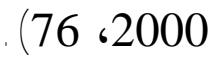

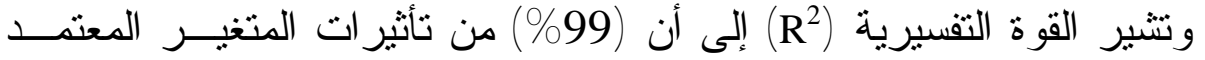

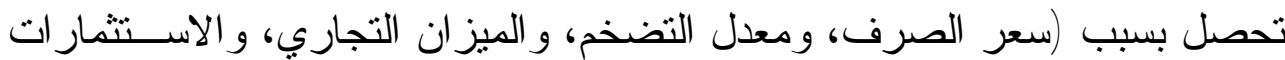

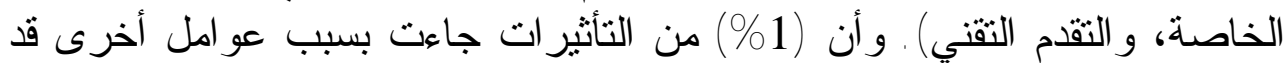

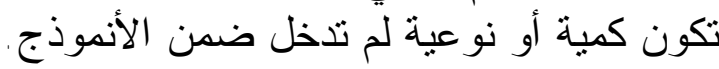

\section{3. مجموعة الدول شبه الصناعية وتم اختيار فيها:}

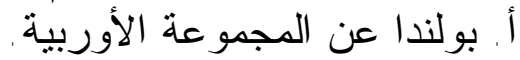

ب. كوريا الجنوبية عن المجموعة الآسيوية.

أ. بولندا

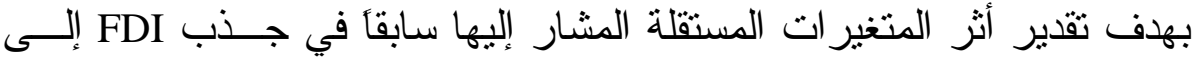

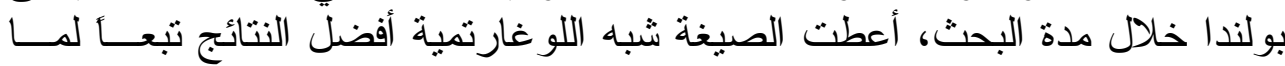

$\log \mathrm{Y}=-1.311+471 \mathrm{x}_{2}-274 \mathrm{x}_{4}-303 \mathrm{x}_{5}+441 \mathrm{x}_{6}$

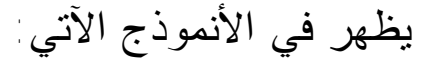

$$
\begin{array}{lll}
\mathrm{t}^{*}=-(3.037) & (3.535)-(2.550)-(3.268)(4.019) \\
\mathrm{R}^{2}=86 \% \quad \mathrm{~F}=50.584 \quad \mathrm{D}-\mathrm{W}=1.782
\end{array}
$$

لقد بلغت قيمة معامل سعر الصرف (471) وحدة، والإشارة الموجبة لمعلمة

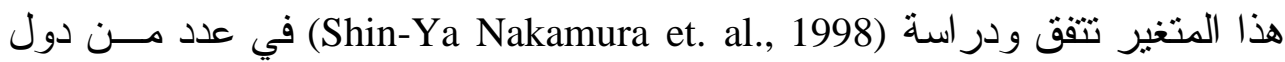

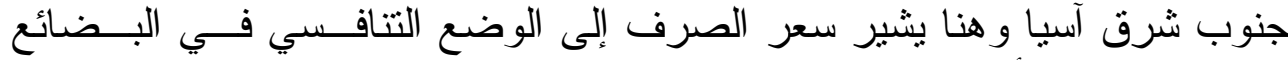

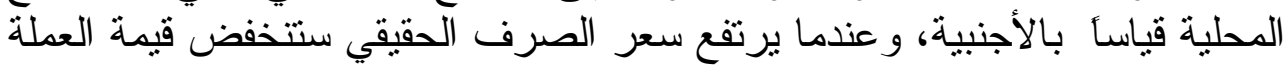

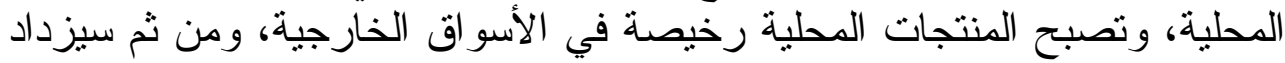

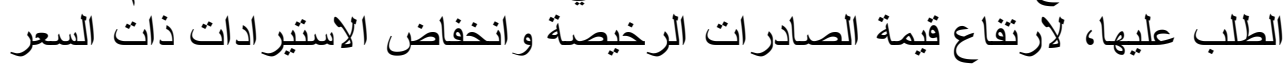

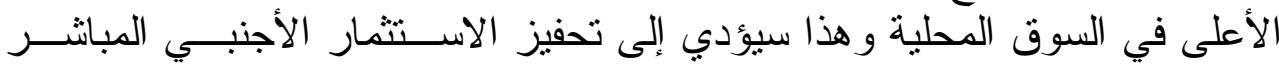
وزيادة تذفقه نحو البلد المضيف الكية. كما وبلغت قيمة معامل الميز ان التجاري (274) وحدة، و الإثــارة الـسالبة

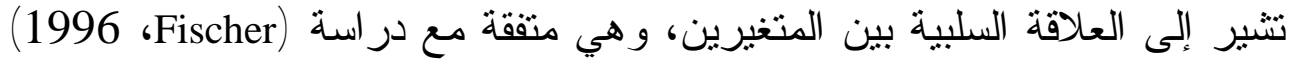

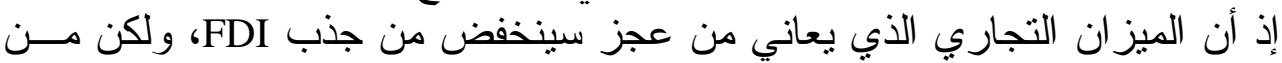

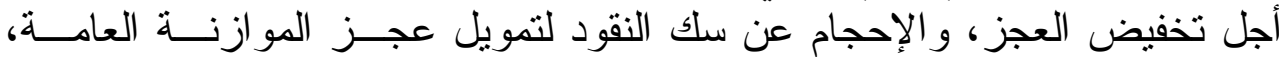




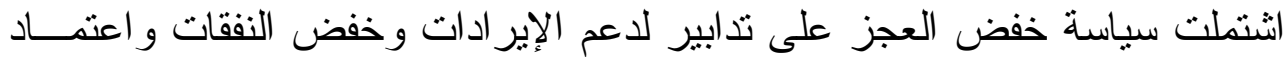

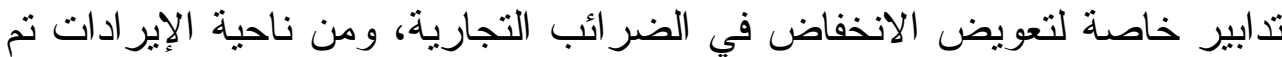

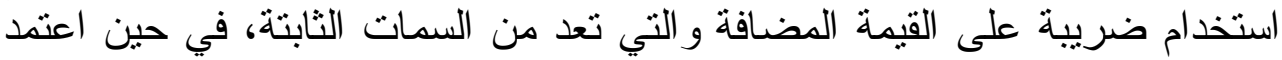

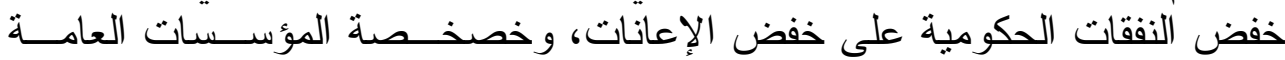
الخاسرة، و هذا ما أثنارت إليه در اسلة (Fischer, 1996, 220).

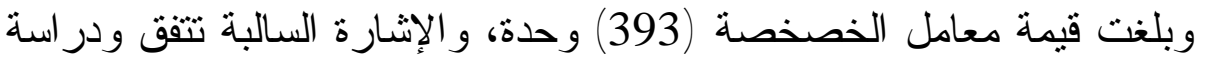
Aziz, Weschott)

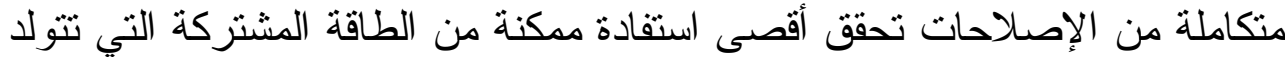

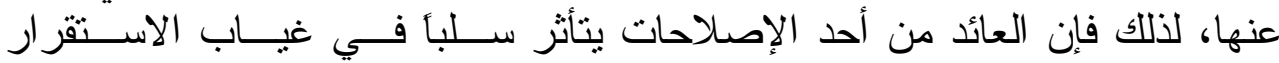

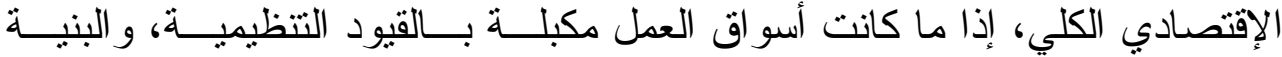

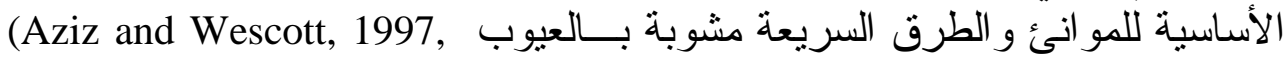
.210)

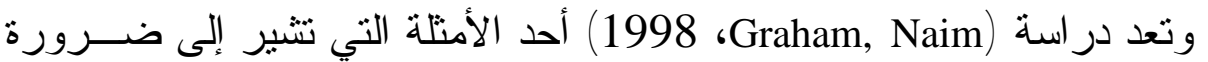

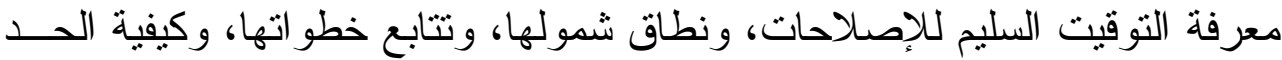

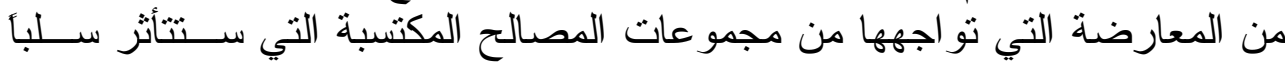

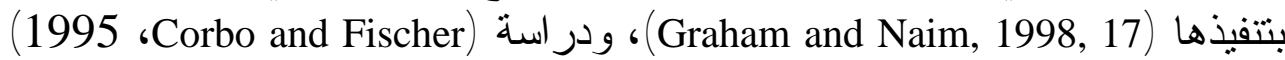

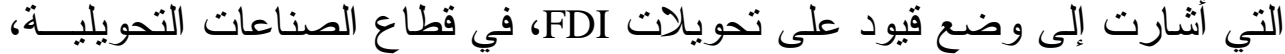

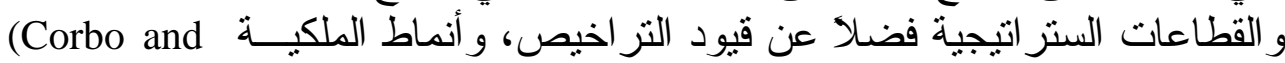
.Fischer, 1995, 30)

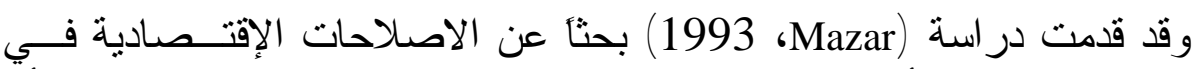

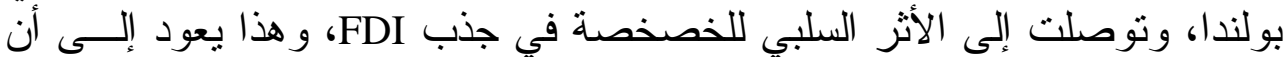

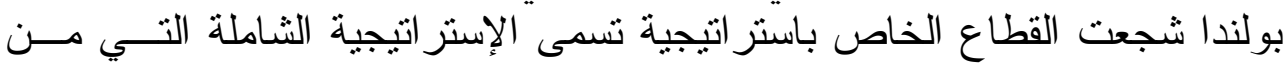

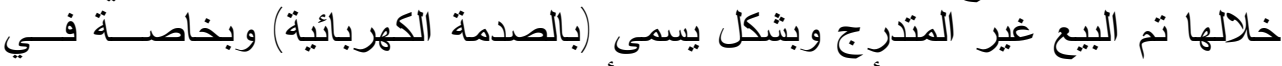

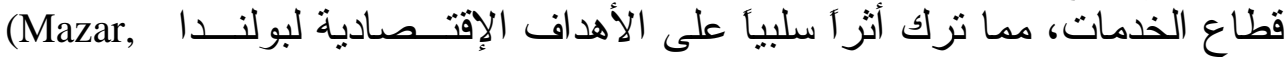
.1993, 45-90)

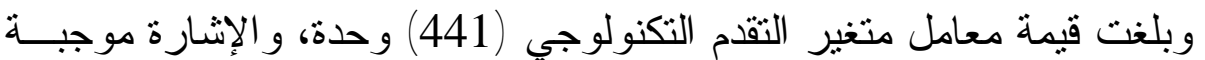

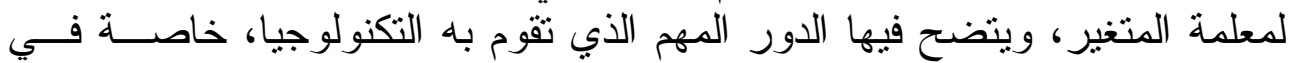

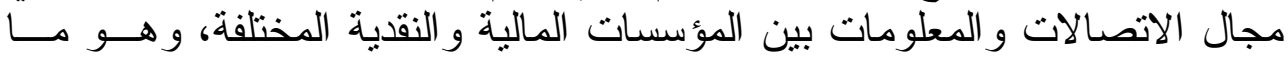
أثنارت إليه در اسة (Bandelj, 2002, 20-23). وتتثير القوة التفسيرية للأنموذج المقدر إلى أن (86\%) من التغير ات التهير الحاصلة

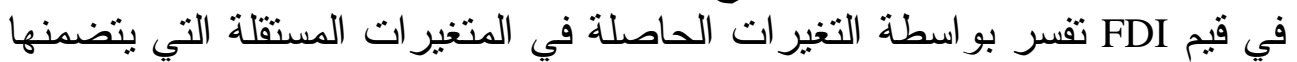

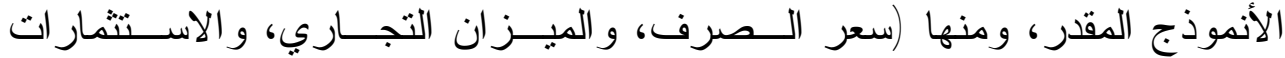

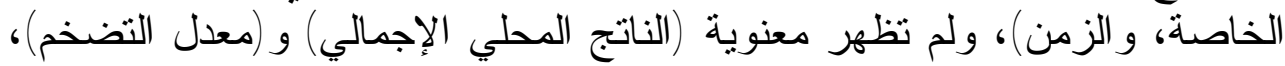
لعدم مقدرة هذين المتغيرين على اجنياز الاختبار ات الإحصائية. 


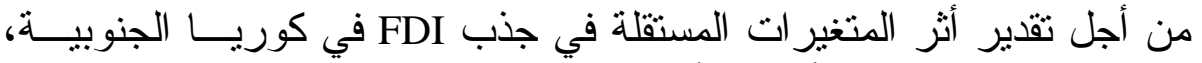

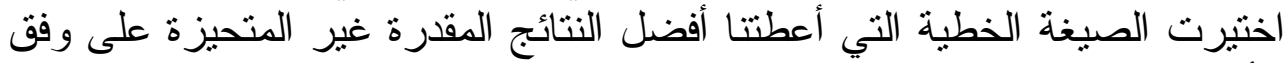

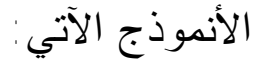

$$
\begin{aligned}
& \mathrm{Y}=43.996-369 \mathrm{x}_{2}+223 \mathrm{x}_{5}+1.074 \mathrm{x}_{6} \\
& \mathrm{t}^{*}=(3.157)-(3.704)(2.687)(8.696) \\
& \mathrm{R}^{2}=93 \% \quad \mathrm{~F}=107.942 \quad \mathrm{D}-\mathrm{W}=1.347
\end{aligned}
$$

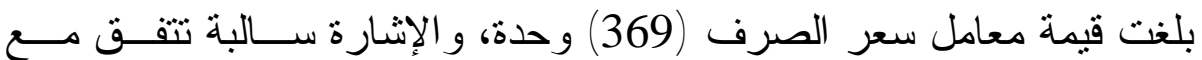

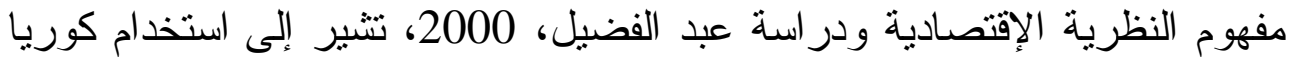

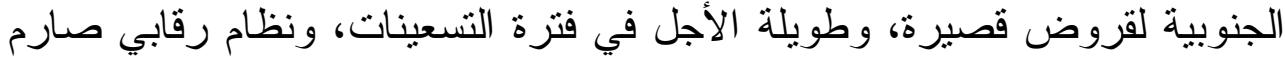

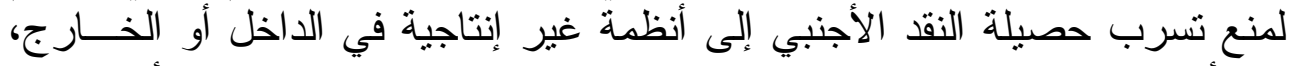

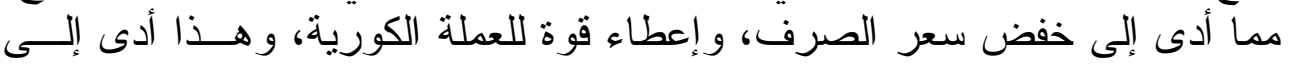

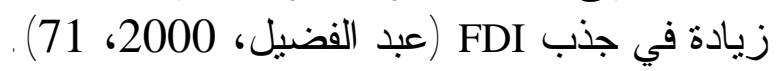

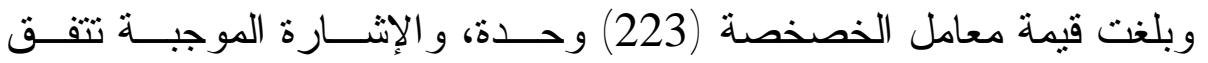

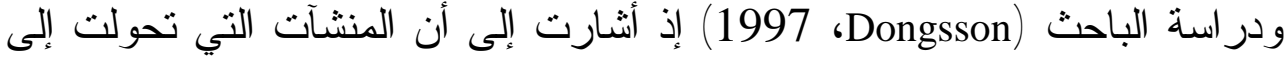

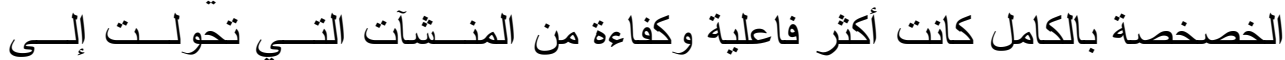

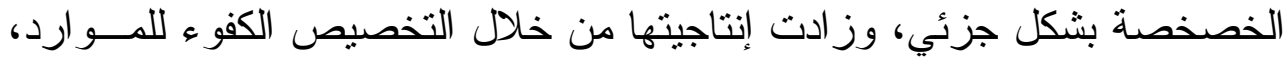

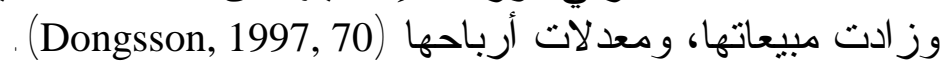

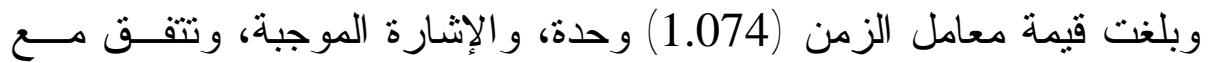

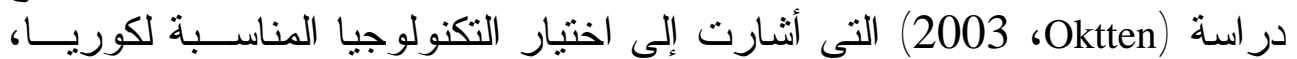

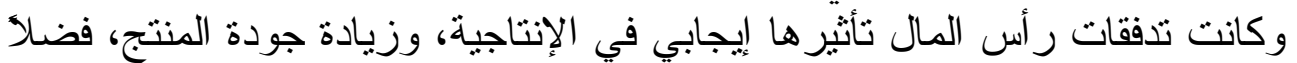

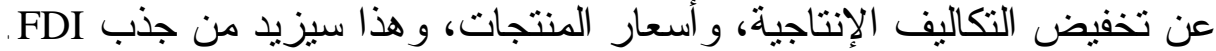

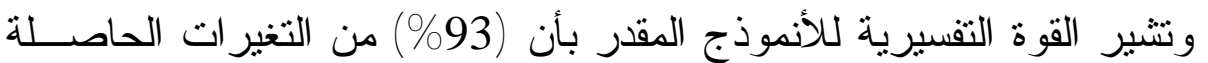

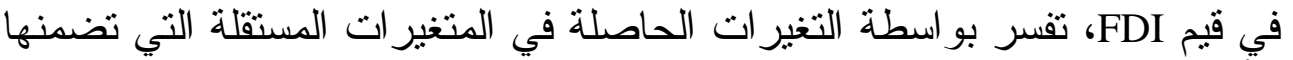

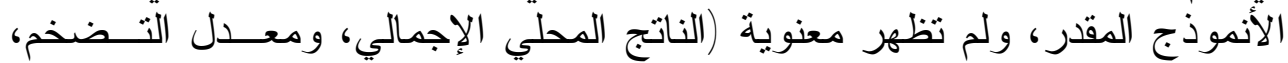
و الميزان التجاري)، لعدم مقدرة هذه المتغير ات على اجتياز الاختبار ات الإحصائية.

4. مجموعة الدول التي في طريقها إلى التصنيع وتم اختيار الدول الاتية: أ. بلغاريا عن المجميو عة الأوربية. ب. باليزيا عن المجموعة الآسيوية.

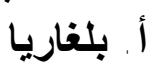

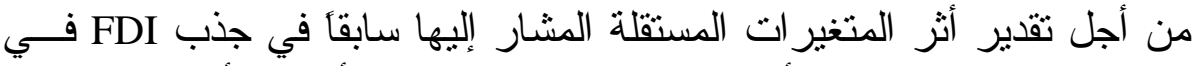

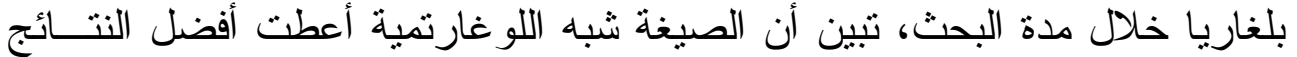

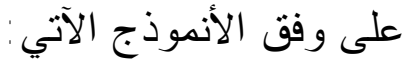


$\log \mathrm{Y}=+276+607 \mathrm{x}_{2}-101 \mathrm{x}_{3}+157 \mathrm{x}_{4}+366 \mathrm{x}_{5}$ $\mathrm{t}^{*}=(1.88)(4.727)-(1.747)(2.75)$

$\mathrm{R}^{2}=1.93 \quad \mathrm{~F}=78.390 \quad \mathrm{D}-\mathrm{W}=1.542$

بلغت قيمة معامل سعر الصرف (607) وحدة، والإشارة الموجبة لمعلمة هذا

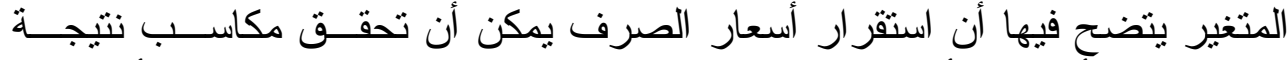

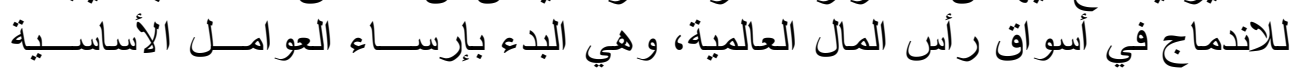

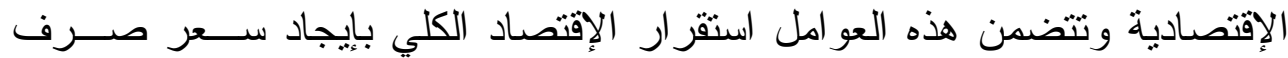

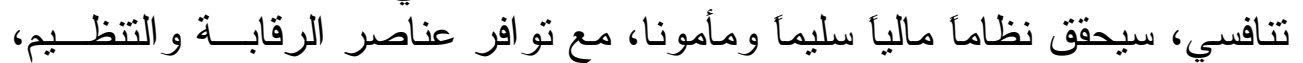

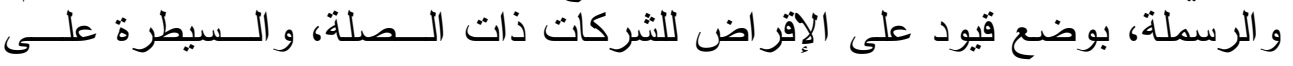

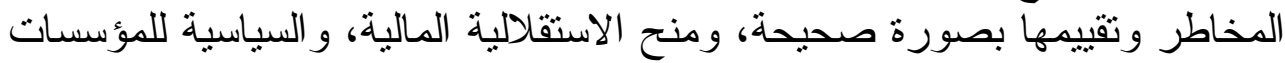

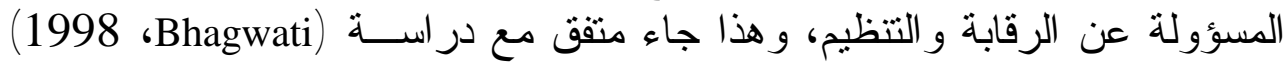

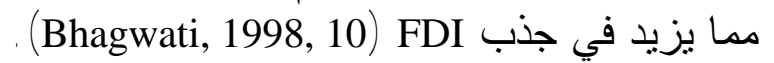

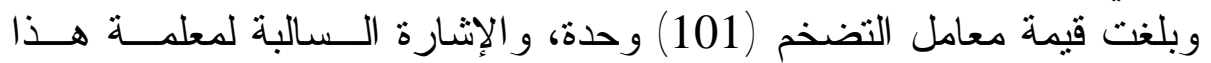

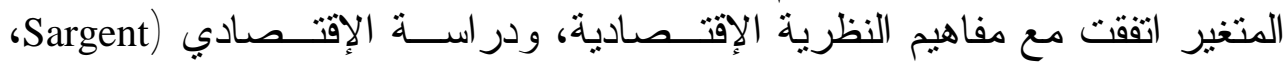

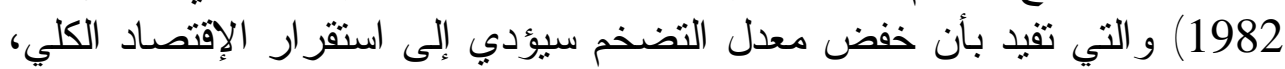

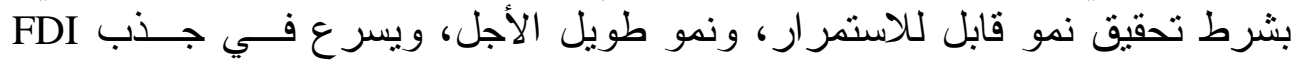
. (Sargent, 1982, 20)

كما وبلغت قيمة معامل الميز ان التجاري (157) وحدة، و الإشارة لمعلمة هذا المتغير الموجبة و المتفقة ودر اسة (العكيدي، 2000) التي تشير إلى أن للاســتشمار

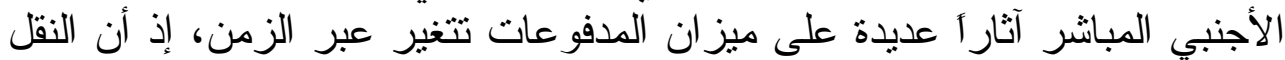

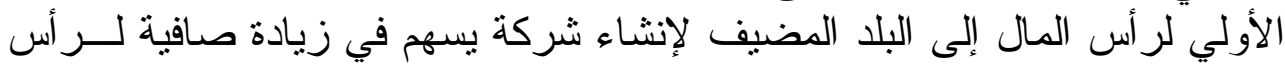
المال، و وعو ائد المشاريع تسجل في حساب رأس المال كتدفق طويل الأجل، وملكية

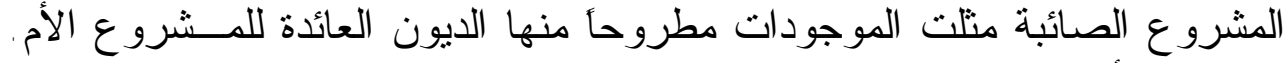

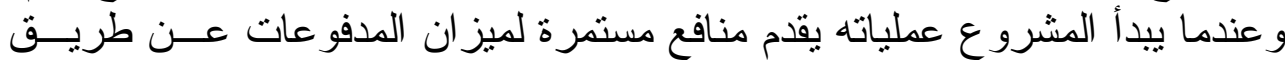

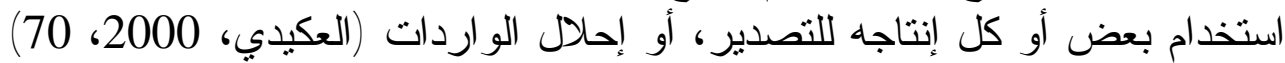

وبلغت قيمة معامل الخصخصة (366) وحدة، وأن الإشارة الموجبة أثبتــت

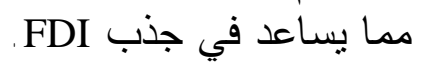

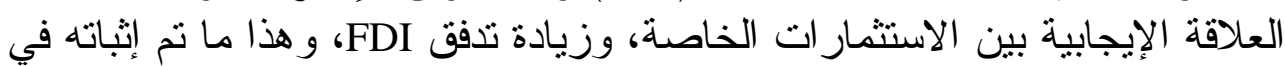

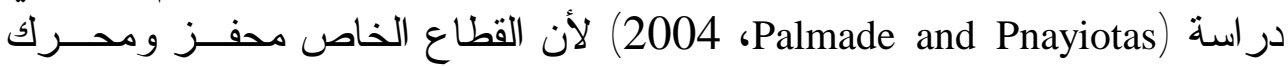

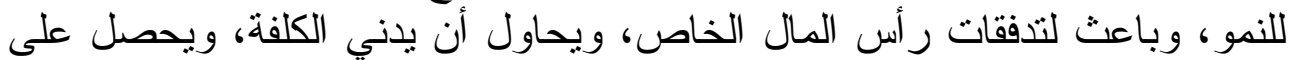

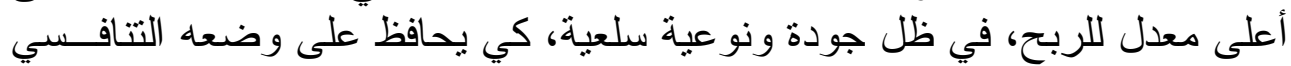
في الأسواق العالمية (Palmade and Pnayiotas, 2004, 274).

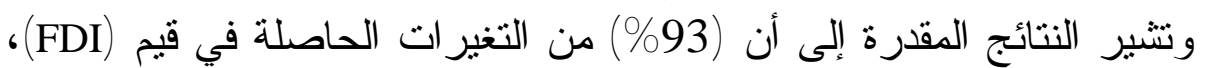
تفسر بو اسطة التغيرات الحاصلة في المتغير ات المستقلة التي يتضمنها الأنمــوذج الته 
المقدر، ولم تظهر معنوية متغير (الناتج المحلــي الإجمـالي) و (الـزمن)، لعـدم مقرتهما على اجتياز الاختبار ات الإحصائية.

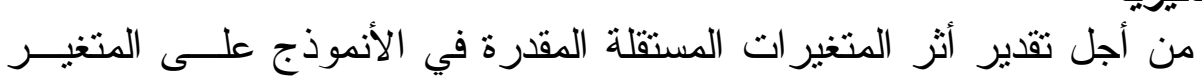

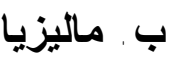

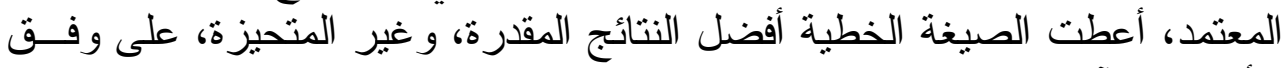

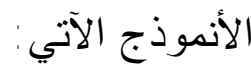

$\mathrm{Y}=113.997-309 \mathrm{x}_{2}-274 \mathrm{x}_{3}-890 \mathrm{x}_{4}+248 \mathrm{x}_{5}+798 \mathrm{x}_{6}$

$t^{*}=(5.12)-(2.34)-(3.09)-(7.15)(2.17)(4.48)$

$\mathrm{R}^{2}=86 \% \quad \mathrm{~F}=28.422 \quad \mathrm{D}-\mathrm{W}=1.492$

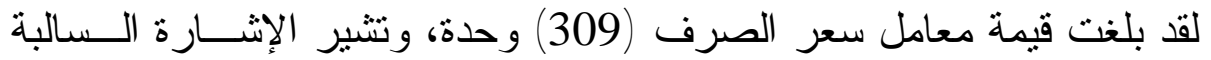

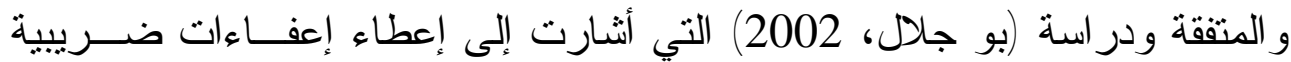

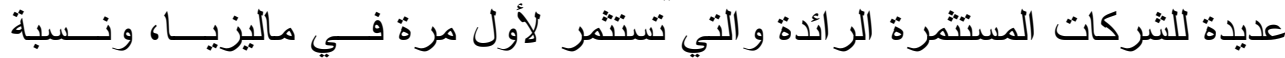

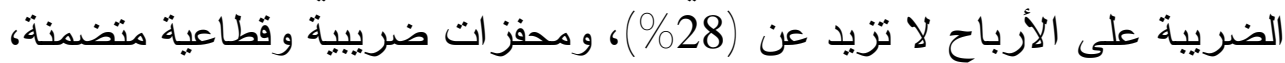

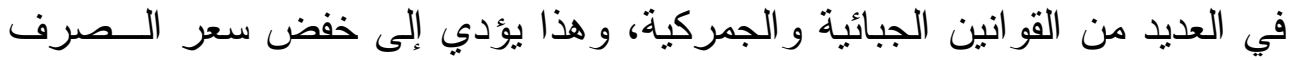

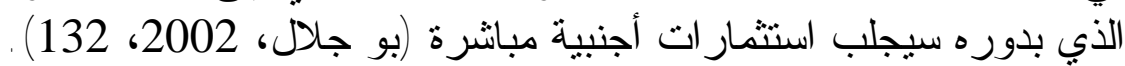

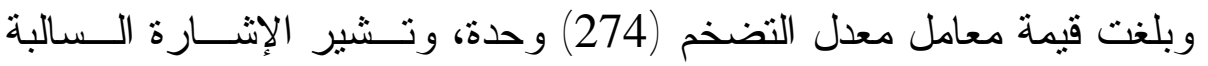

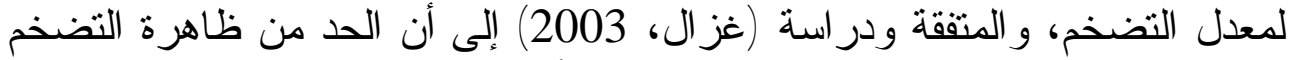

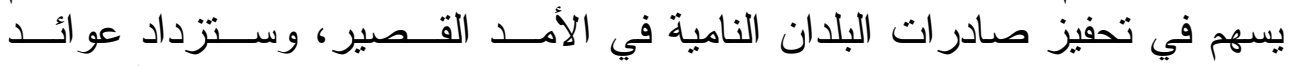

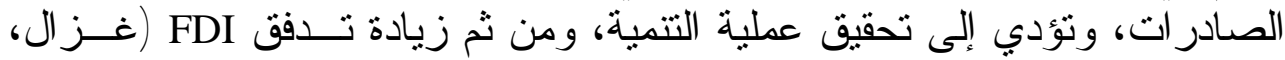
2003، 169 (169)

كما وبلغت قيمة معامل المبزان التجاري (890) وحدة، و الإثــارة الـسالبة

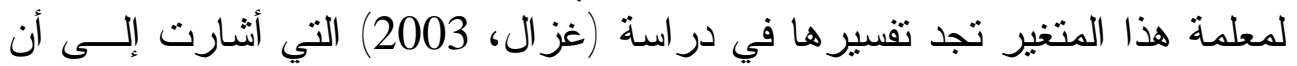

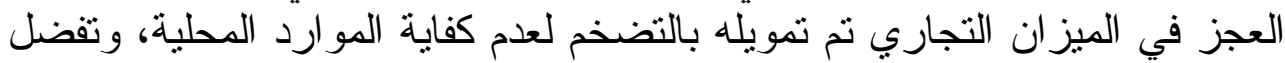

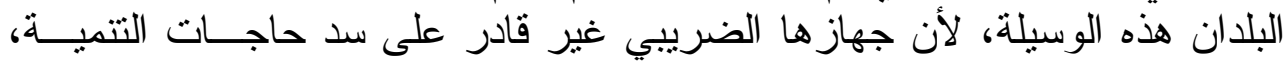

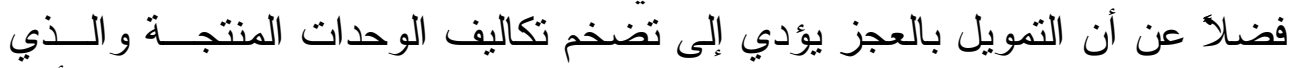
سيؤدي إلى خفض الكلفة الإقتصادية للقطاعات، وكلما انخفض التضان التمويل بالعجز أدى النى

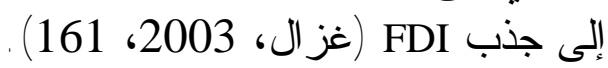

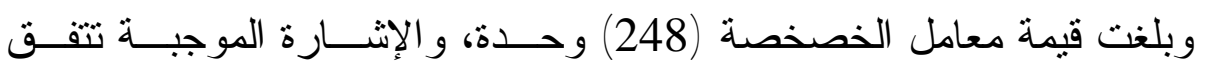
ودراسة (عبد الفضيل، 2000) التي نتشير إلى دور الدولة الفاعل في إجراء التهاء عملية

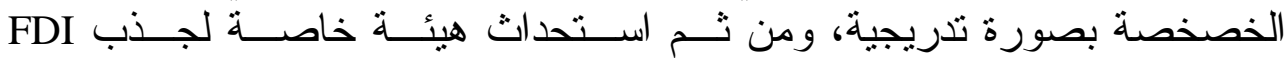
و المستثمرين الأجانب، مع تقديم المساعدة الفنية للذين ير غبون في إقامــة أنسشطة 


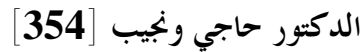

على الأراضي الماليزية، أدى إلى جذب FDI إلى ماليزيا (عبد الفـضيل، 2000،

كما وبلغت قيمة معامل الزمن (798) وحدة، ويتضح من الإثـارة الموجبة لها

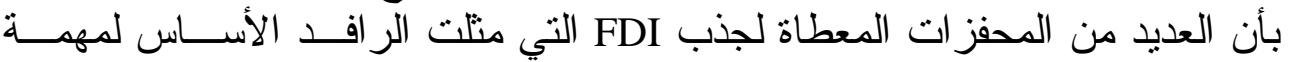

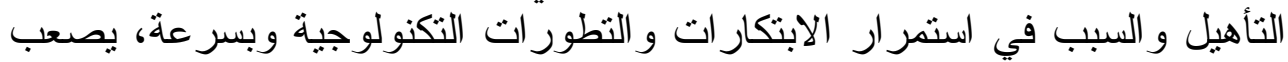

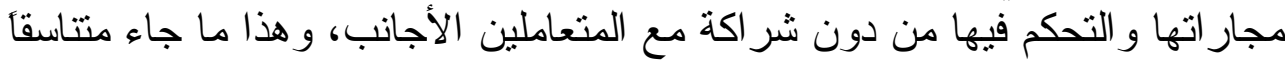

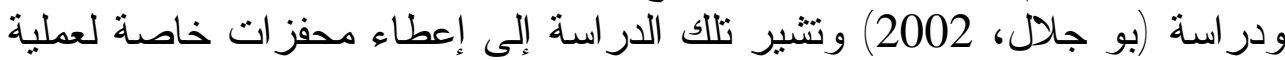

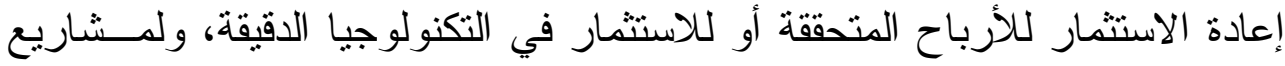

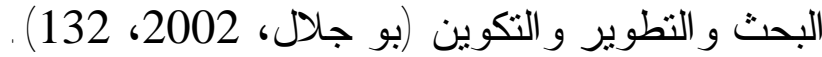

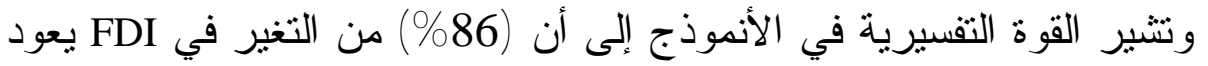

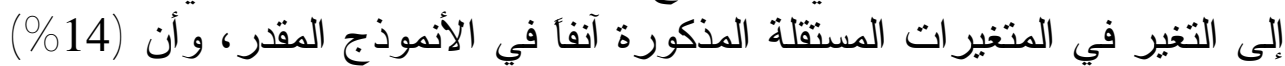
من التغير ات تعود لأسباب كمية أو نو عية غير مقاسة لم تدخل في الأنموذج.

الاستنتاجات و المقترحات

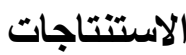

إن أهم الاستتناجات المستخلصة من البحث كانت على النحو الآتي:

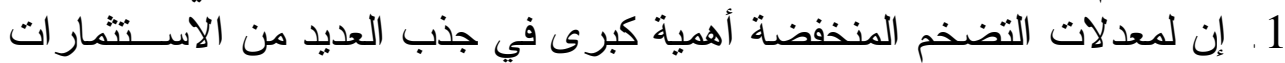
الأجنبية المبانشرة، و العكس في حالة الإرتفاع.

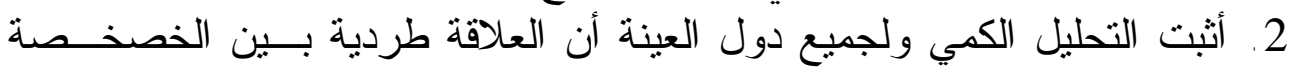

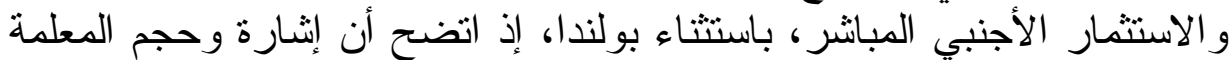

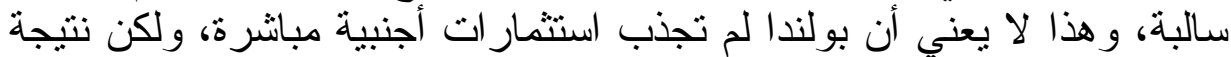

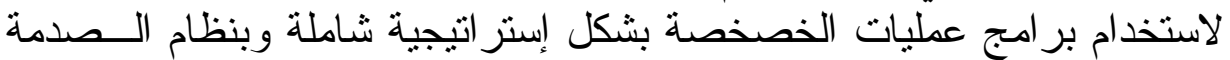

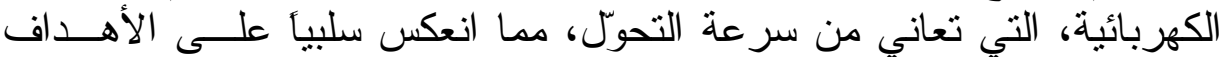
الإقتصادية و الاجتماعية للاولة التئ.

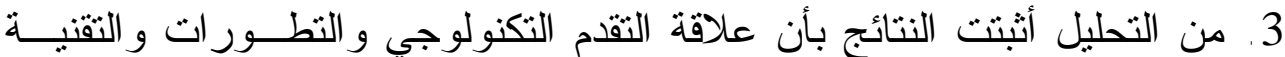

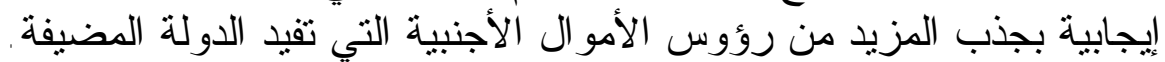

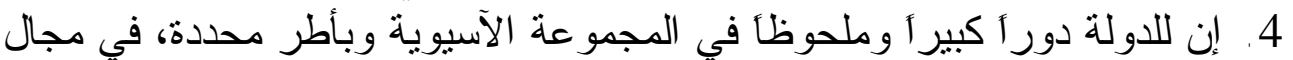

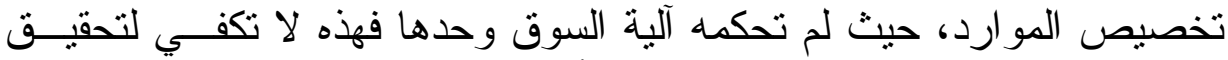

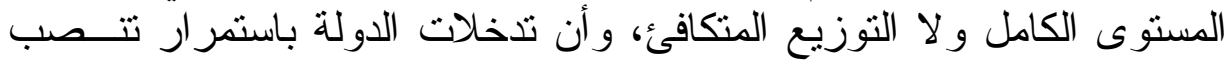

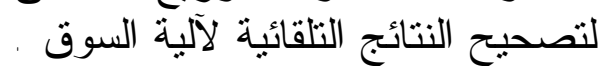

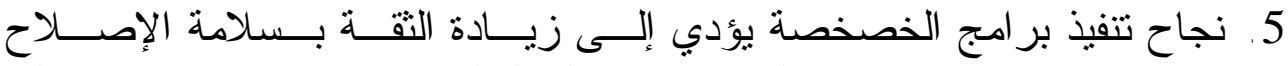

الإقتصادي وبخاصة فيما يتعلق بإعادة هيكلة القطاعات الإنتاجية، مما يؤدي الإنى الإنى زيادة تسار ع معدلات النمو في الإقتصاد القومي.

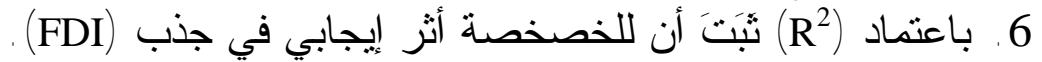


7. كما أظهر التحليل أن تدفقات الاستثمار الأجنبي المباشر تتجه نحــو مجموعــة الدول الصناعية وشبه الصناعية.

المقترحات

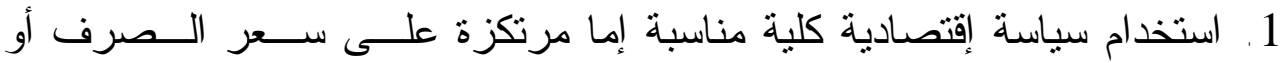

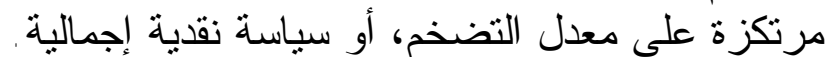

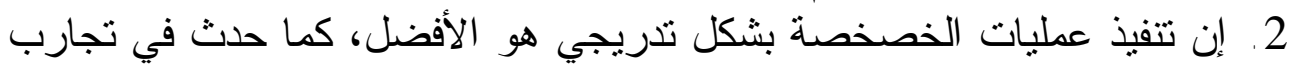

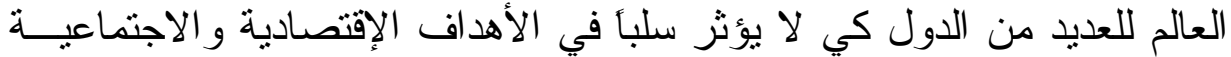

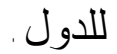

3. ضرورة وجود التز ام سياسي لتنفيذ برنامج الخصخصة، اذ يضمن ذلك إثر الك

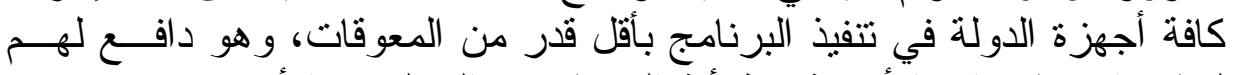

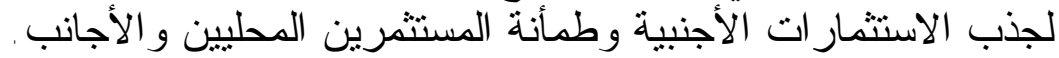

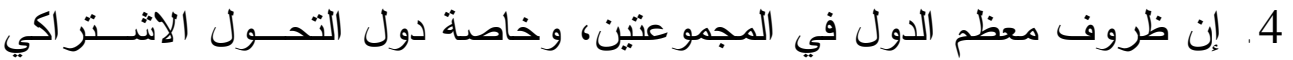

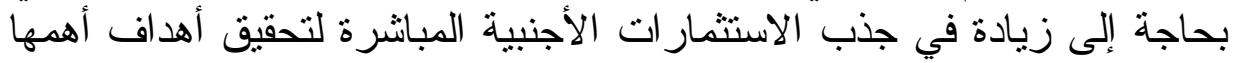

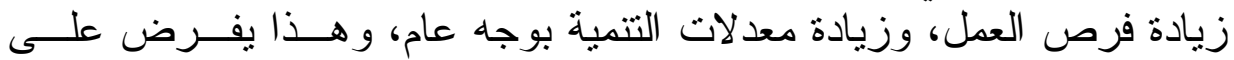

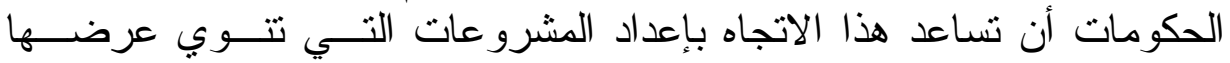
للاستثمار بو اسطة القطاع الخاص.

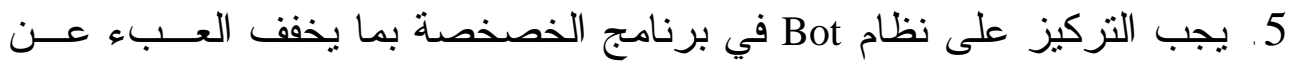
الحكومة و المو ازنة العامة.

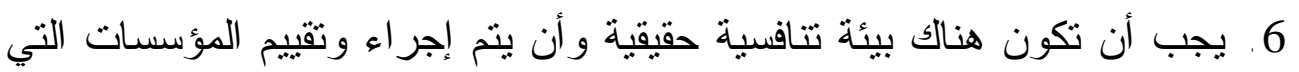

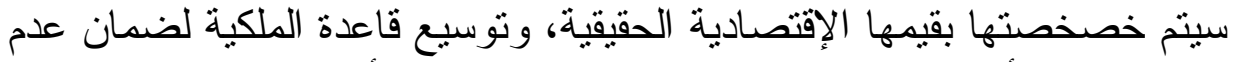
الانتقال من ر أسمالية الدولة إلى احتكار مجموعة من الإنة الأفر اد. . 7. 8. مقترحنا للباحثين بإجر اء دراسة في أثز التكتلات الإقتصادية في جذب التب الاستثمار

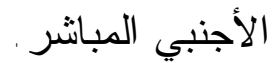

\section{أولا - المراجع باللغة العربية}

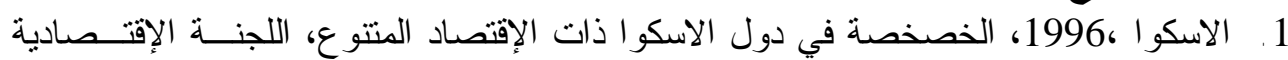

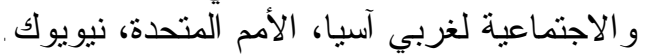

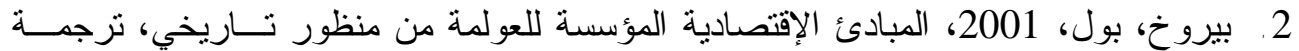

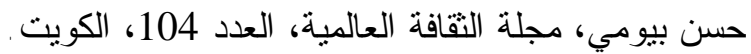

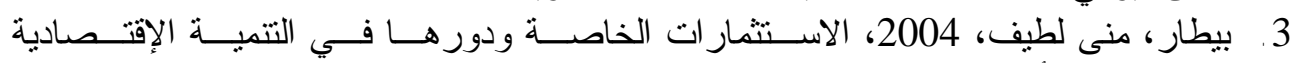

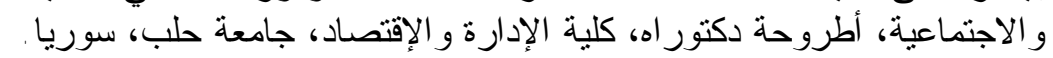

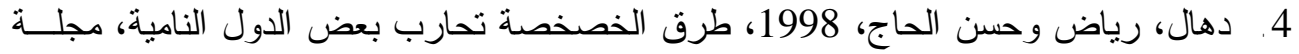
بحوث إقتصادية، الجمعية العربية للبحوث، العدد 134. 


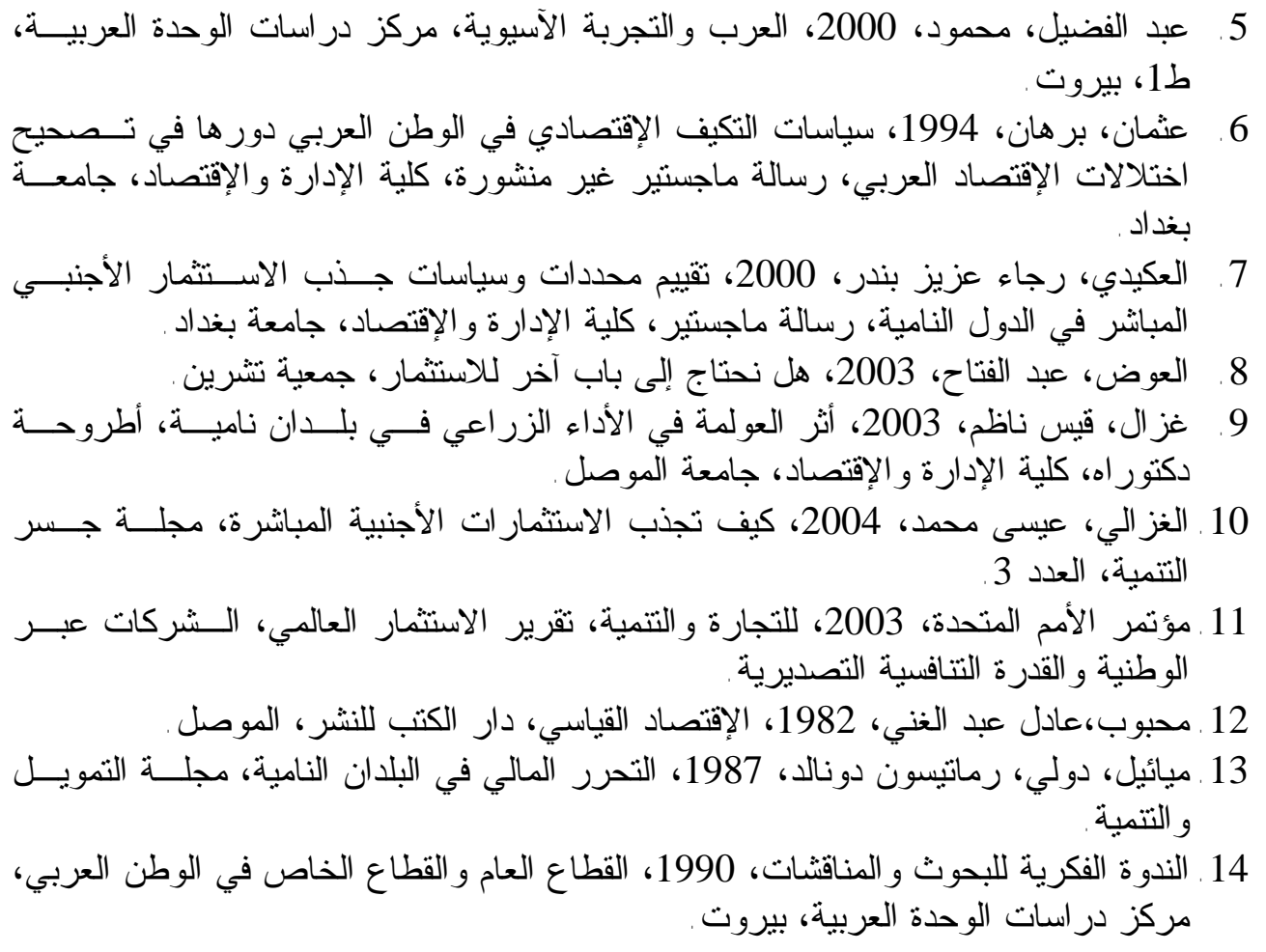

\section{ثانياً - المر اجع باللغة الأجنبية}

1. A. Kouts yiannis 1977, "Theory of econometrics", second edition, the Macmillan Press Ltd, London.

2. Ahmed Midiyad 1995, The Social Balance Sheel of Privatization in Arab Countries the third vordic conference of Middle Eastern Studies: www.HF.uibndino/institutter/smi/paj/jiyad.htm.

3. Ana Mria 1999, "Capital Flow and Capital Control", Institute Brazilin Business and Public Management, George Washington University.

4. Aziz, J. and Wescott, R 1997 "Policy Complementarities and the Washington Consensus", IMF Working Paper Washington, D. C.: International Monetary Fund.

5. Bennedsen, M. 2000, "Political ownership", Journal of public Economics, London. 76.

6. Bhagwat, J. 1991, Political Economy and International Economics, Cambridge Massachusetts: Mlteress, London.

7. Caves, R. 1996, Managing Fiscal Policy in Latin America, IDB working paper No. 3260 Washington, D. C. inter America Development Bank.

8. Chang Alphac 1984, Fundamental Methods of Mathematical Economics, Third Edition, McGraw-Hill, Company New York USA, Singapore.

9. Darnbush, R. 1997, "Brazils Complete stabilization and Reform", Bookings Papers on Economic Activity, 1.

10. E. D. Domdr 1950, "The effect of foreign investment on the balance of payments", American Economic Review, London.

11. Edward M. Graham 1998, Foreign Direct Investment in World Economy, World Economic and Financial Survey, staff for the world economic out look IMF, London .

12. ESCWA 2000, The Role of Foreign Direct Investment in Economic Development in ESCWA Member Countries, UN, New York, U.S.A. 
13. Fischer, S. 1996, "The Role of Maero economic factors in economic growth, Journal of Monetary Economics, London 32, 3.

14. IMF 1997, World Economic out look, the Information Technology Revolution, Washington.

15. International Financial Statistical 1979, 2003, Handbook, New York, Geneva.

16. Jack. D, Gglen \& Mazar, A. 1993, Sumlinski, London.

17. Krugman, P. 1992, "Is Free Trade Pass", Journal of Economic Perspectives, London 1, 2.

18. Len, J. Trevion, John D. Daniels and Harvey Arbelaez 2002, "Market reform and FDI in Latin America an empirical investigation, unctad, Vol. 1, A. 1.

19. Mina Bandelh 2002, Greartion of Foreign Direct Investment markets in central and eastern Europe, Department of Sociology Princeton University. N hanbelj princetion, edu.

20. Sargent, T 1982, "The End of Four Big Inflations", in Inflations: Causes and effect, Chicago University Press.

21. Unctad 1997, World Investment Report: Transnational Corporation, Market Structure and Competition Policy, Un, New York, Geneva.

22. Unctad 1998, World Investment Report Trends and Determinate New York, Geneva.

23. Unctad 1999, World Investment Report, United Nations, New York, Geneva.

24. Vincent Palmade and Andrea Anayitas 2004, Private Sector Development VICE presidency the World Bank Group upalmad@ifc.org.

1. www.mackinace.org/speechs/privatiz.htm

2. www.oced.org/search97cgi/sminimagepath.

3. www.eia.doe.gov/emeu/pgem/chlb.htm

4. www.alrydh.up.com

5. www.worldbank.org/cgi

6. www.GlobalDevelopmentNetwork.org/htm

7. www.economic.ox.ac.u

8. www.Griffin\&pustay

9. www.wto.org/ecommerce/0066/pdf.15

10. www.islamonline.net/iol-aralnc/dowalia/namma44.moragoat.asp 